\title{
A Multifactorial Approach for Sarcopenia Assessment: A Literature Review
}

\author{
Rashmi Supriya ${ }^{1, *(\mathbb{D})}$, Kumar Purnendu Singh ${ }^{2}$, Yang Gao ${ }^{1} \mathbb{D}$, Feifei Li ${ }^{1} \mathbb{D}$, Frédéric Dutheil ${ }^{3} \mathbb{D}$ \\ and Julien S. Baker ${ }^{1}$ (D)
}

1 Centre for Health and Exercise Science Research, Sarcopenic Research Unit, Department of Sport, Physical Education and Health, Hong Kong Baptist University, Kowloon Tong, Hong Kong 999077, China; gaoyang@hkbu.edu.hk (Y.G.); lifeifei@hkbu.edu.hk (F.L.); jsbaker@hkbu.edu.hk (J.S.B.)

2 FEBT, School of Environment, Resources and Development, Asian Institute of Technology, Klong Luang, Bangkok 12120, Thailand; purnendusin@gmail.com

3 University Clermont Auvergne, CNRS, LaPSCo, Physiological and Psychosocial Stress, CHU Clermont-Ferrand, University Hospital of Clermont-Ferrand, Preventive and Occupational Medicine, Witty Fit, F-63000 Clermont-Ferrand, France; frederic.dutheil@uca.fr

* Correspondence: rashmisupriya@hkbu.edu.hk

check for updates

Citation: Supriya, R.; Singh, K.P.; Gao, Y.; Li, F.; Dutheil, F.; Baker, J.S. A Multifactorial Approach for Sarcopenia Assessment: A Literature Review. Biology 2021, 10, 1354. https://doi.org/10.3390/ biology10121354

Academic Editor: Carlo Reggiani

Received: 11 November 2021 Accepted: 18 December 2021 Published: 20 December 2021

Publisher's Note: MDPI stays neutral with regard to jurisdictional claims in published maps and institutional affiliations.

Copyright: (c) 2021 by the authors. Licensee MDPI, Basel, Switzerland. This article is an open access article distributed under the terms and conditions of the Creative Commons Attribution (CC BY) license (https:// creativecommons.org/licenses/by/ $4.0 /)$.
Simple Summary: Sarcopenia is characterized by an accelerated decline in skeletal muscle mass and strength, which results in poor quality of life, disability, and death. In the literature, sarcopenia is defined as the progressive breakdown of muscle tissue. The prevalence ranges from $5 \%$ to $13 \%$ in people $60-70$ years old and from $11 \%$ to $50 \%$ in people older than 80 years. The comparison of risk factors associated with sarcopenia based on the European Working Group on Sarcopenia (1 and 2) in Older People, the Asian Working Group for Sarcopenia (1 and 2), the International Working Group on Sarcopenia, and the Foundation for the National Institutes of Health revealed no consistent patterns. Accordingly, the identification of a single risk factor for sarcopenia is unpredictable. Due to its "multifactorial" pathogenesis related to the involvement of a multitude of factors. In this review, we summarize 13 relevant risk factors associated with this disease that are important to consider prior to embarking on any related sarcopenia research. We suggest that researchers should concentrate on the biology of sarcopenia to develop a uniform consensus for screening this condition. In this review, we identify 50 biochemical markers across six pathways that have previously been investigated in subjects with sarcopenia. We suggest that these summarized biomarkers can be considered in future diagnosis to determine the biology of this disorder, thereby contributing to further research findings. As a result, a uniform consensus may also need to be established for screening and defining the disease. Sarcopenia is associated with a number of adverse economic and social outcomes, including disability, hospitalization, and death. In relation to this, we propose that we need to develop strategies including exercise interventions in the COVID-19 era to delay the onset and effects of sarcopenia. This suggestion should impact on sarcopenia's primary and secondary outcomes, including physical, medical, social, and financial interactions.

Abstract: Sarcopenia refers to a progressive and generalized weakness of skeletal muscle as individuals age. Sarcopenia usually occurs after the age of 60 years and is associated with a persistent decline in muscle strength, function, and quality. A comparison of the risk factors associated with sarcopenia based on the European Working Group on Sarcopenia (1 and 2) in Older People, the Asian Working Group for Sarcopenia (1 and 2), the International Working Group on Sarcopenia, and the Foundation for the National Institutes of Health revealed no consistent patterns. Accordingly, the identification of a single risk factor for sarcopenia is unpredictable due to its "multifactorial" pathogenesis, with the involvement of a multitude of factors. Therefore, the first aim of this review was to outline and propose that the multiple factors associated with sarcopenia need to be considered in combination in the design of new experimentation in this area. A secondary aim was to highlight the biochemical risk factors that are already identified in subjects with sarcopenia to assist scientists in understanding the biology of the pathophysiological mechanisms affecting the old people with sarcopenia. We also briefly discuss primary outcomes (physical) and secondary outcomes (social 
and financial) of sarcopenia. For future investigative purposes, this comprehensive review may be useful in considering important risk factors in the utilization of a panel of biomarkers emanating from all pathways involved in the pathogenesis of this disease. This may help to establish a uniform consensus for screening and defining this disease. Considering the COVID-19 pandemic, its impact may be exacerbated in older populations, which requires immediate attention. Here, we briefly suggest strategies for advancing the development of smart technologies to deliver exercise in the COVID-19 era in an attempt regress the onset of sarcopenia. These strategies may also have an impact on sarcopenia's primary and secondary outcomes.

Keywords: sarcopenia; biomarkers; genetic factors; psychosocial factors; behavioral risk factors; literature review

\section{Introduction}

Sarcopenia is a clinical condition in which skeletal muscle mass and strength gradually decline, leading to adverse outcomes including poor quality of life, disability, and death $[1,2]$. Sarcopenia is defined in the literature as a progressive degeneration of muscle tissue, with a prevalence range of $5-13 \%$ in people $60-70$ years of age, and $11-50 \%$ in people $>80$ years [3]. Approximately 600 million people worldwide were classified as being over 60 years old in 2000. By 2025, this number is predicted to grow to 1.2 billion, with further increases to 2 billion as the years progress [4]. Based on the most conventional estimates, sarcopenia could affect more than 200 million people in 40 years' time. In terms of mortality and morbidity, sarcopenia impacts older people greatly, causing substantial costs in terms of health care, disability, and morbidity $[5,6]$. Geriatricians and scientists in Europe and Asia have devised diagnostic criteria for sarcopenia that can be used worldwide as a clinical and public health methodology. An agreement on defining sarcopenia, as well as diagnostic criteria, was first proposed by the European Working Group on Sarcopenia for Older People (EWGSOP1) in 2010 [7]. Following this, an international sarcopenia definition was formulated by the International Working Group on Sarcopenia (IWGA) in 2011 [8]. In 2014, the Asian Working Group for Sarcopenia (AWGS1) released its regional guidelines to support research on sarcopenia in Asia [9]. Later, the Foundation for the National Institutes of Health (FINH) began its work on the sarcopenia project in $2014[10,11]$. Again a new version of the EWGSOP2 was published in 2018 to update the definition and diagnosis of sarcopenia [12]. Recently, sarcopenia research in Asia was promoted as part of revised guidelines by the Asian Working Group for Sarcopenia (AWGS2) in 2019 [13].

Sarcopenia is indicated by persons with a low muscle mass, weak handgrip strength, or slow walking speed as defined by EWGSOP criteria, but based on IWGS criteria, sarcopenia is defined as slow walking speed and reduced muscle mass in the body. There is only very limited agreement between IWGS and EWGSOP when defining sarcopenia, and its prevalence varies greatly when measuring skeletal muscle mass. Selecting the optimal cutoff values for handgrip strength, walking speed, and skeletal muscle indices, taking into account gender and ethnicity differences, is crucial for achieving universal diagnostic criteria for sarcopenia [14]. Sarcopenia is defined differently by the EWGSOP2 criteria than by EWGSOP1, AWGS, IWGA, and FNIH. A comparison of the risk factors associated with sarcopenia defined by EWGSOP2 with those defined by EWGSOP1, AWGS, IWGA, and FNIH does not reveal any consistent patterns. In light of this, prospective studies are needed in order to confirm the validity of EWGSOP2 or AWGS2 [15]. The WCHAT study, a trial of West China Health and Aging Trends in western China, provided baseline data for a study that was conducted in 2021 to investigate the prevalence and associated risk factors for sarcopenia in 4500 participants. Measurement of muscle mass was performed using bioimpedance analysis (BIA). A measurement of handgrip strength and measures of walking speed were also recorded. A variety of variables were collected, such as anthropometry measurements, lifestyle, chronic diseases, and blood tests. AWGS2 and 
IWGS provided independent correlations between serum albumin level and sarcopenia. EWGSOPT2 and FNIH both showed an independent association between vitamin D level and sarcopenia. AWGS1 significantly associated age, depressive status, body mass index (BMI), hemoglobin, vitamin D, and insulin level with sarcopenia, but AWGS2 did not associate any of these factors with sarcopenia. Various sarcopenic criteria are principally associated with low serum albumin levels and low vitamin D levels. Most risk factors associated with AWGS1 defining sarcopenia have not consistently been observed in AWGS2. In addition to such prospective studies, a multi-pronged approach for treating this disease is required to confirm the validity of the AWGS2 consensus [16].

As sarcopenia has serious and life-changing effects on older people, health professionals around the world need to synergize and collaborate to translate our growing body of knowledge into practical actions that will positively impact millions of older people globally. In the fourth decade of life, skeletal muscle mass and strength decline linearly. By the eighth decade of life, $50 \%$ of skeletal muscle mass is lost [17]. It is estimated that sarcopenia affects $5 \%$ to $13 \%$ of community-dwelling older people over 65 years. Those older than 80 and those who live in residential care or hospitals are more likely to be affected by this condition [18]. A person's muscle mass decreases at a rate of about $8 \%$ per decade from the age of 50 until 70 years, where it is accelerated by about $15 \%$ per decade [19]. Nonetheless, many individuals continue to debate what the appropriate cutoff value is for diagnosing sarcopenia and, more practically, what the most effective screening tool should be [17]. A comparison of the risk factors associated with sarcopenia based on EWGSOP (1 and 2), AWGS (1 and 2), IWGS, and FNIH revealed no consistent patterns. Therefore, the identification of a single risk factor for sarcopenia is unreliable due to its "multifactorial" pathogenesis, with the involvement of a multitude of factors. The primary objective of this review was to compile information related to the multiple factors associated with sarcopenia based on studies outlined by the working organizations for this condition (Figure 1) to facilitate future studies. A further aim was to describe the pathophysiological mechanisms of sarcopenia, and in an attempt to determine the patient's condition, a panel of biomarkers has been proposed that comprise six major pathways (Figure 2) involved in sarcopenia that may need to be evaluated and summarized for future diagnosis. This may help determine the biological pathways of the disease, contributing to further research. This may also contribute to establishing a uniform consensus for screening and defining the disease. Additionally, we discuss the impact of sarcopenia individually, socially, and financially. Finally, we emphasize that its impact during the COVID-19 pandemic may be exacerbated in older populations, which require scrutiny and investigation as a matter of urgency. 


\section{SARCOPENIA A MULTIFACTORIAL DISEASE}

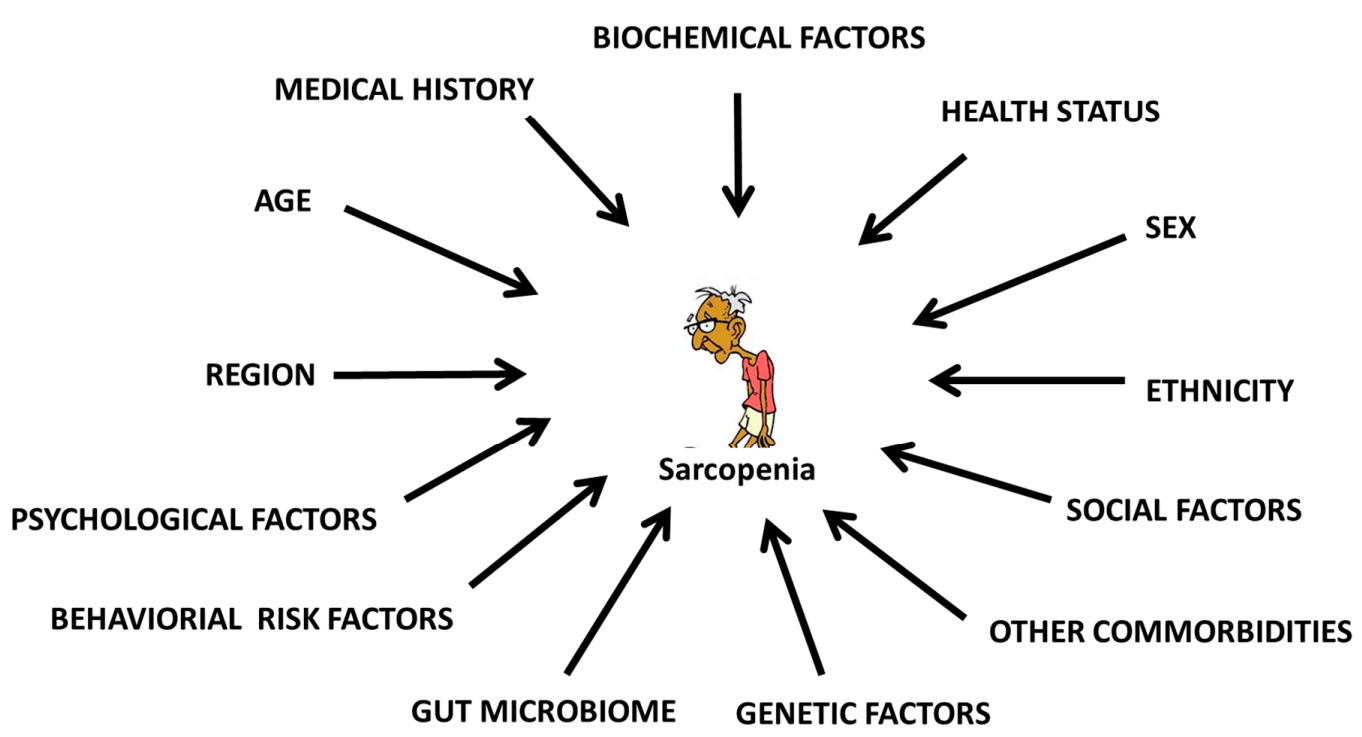

Figure 1. Sarcopenia associated with multiple factors including age, sex, region, ethnicity, medical history, health status, psychological factors, social factors, behavioral factors, gut microbiome, genetic factors, other comorbidities, and biochemical factors.

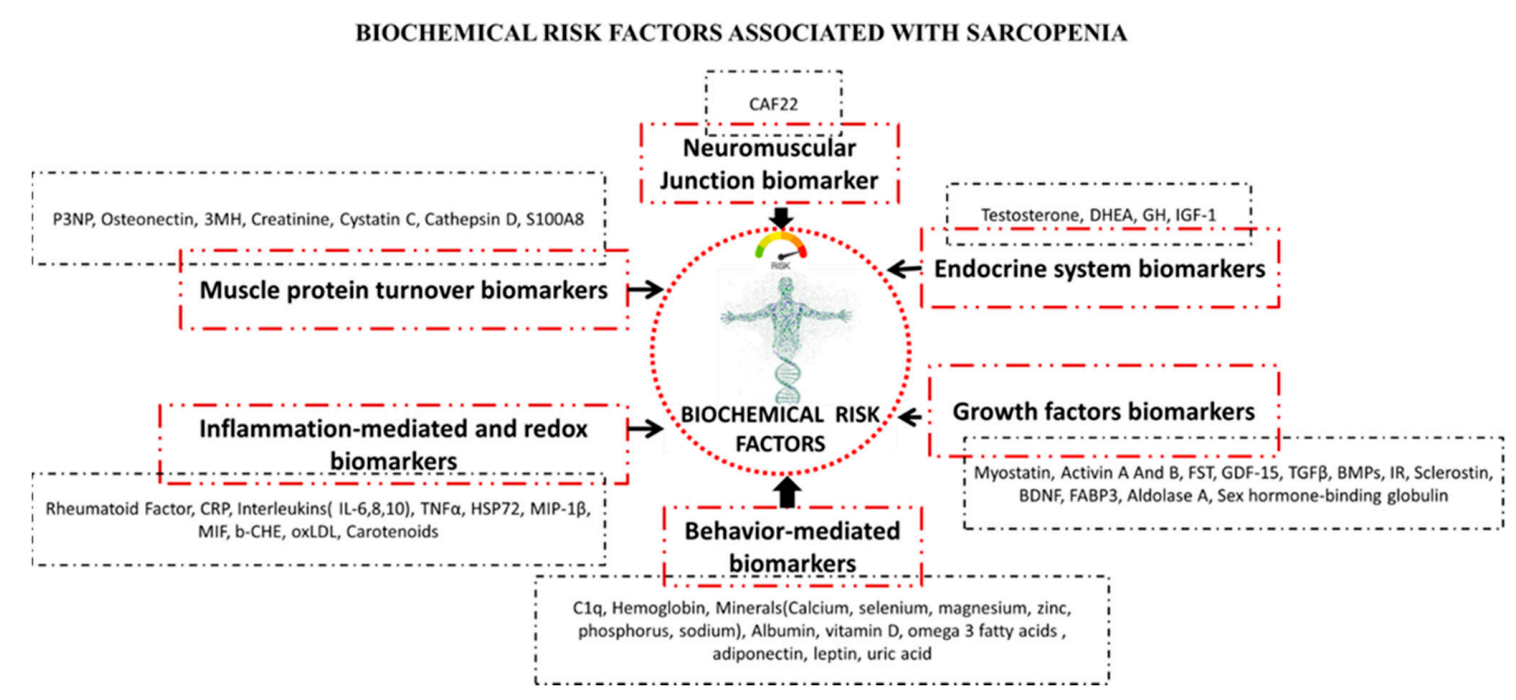

Figure 2. Biochemical risk factors are contributed by different pathways. Biomarkers associated with people with sarcopenia based on different pathways include neuromuscular junction biomarkers (CAF22); endocrine system biomarkers (T, DHEA, GH, IGF1); growth factors biomarkers (myostatin activin A and B, FST, GDF-15, TGF $\beta$, BMPs, IR, sclerostin, BDNF, FABP3, aldolase A, sex hormone-binding globulin); behavioral-mediated biomarkers (C1q, hemoglobin, minerals (calcium, selenium, magnesium, zinc, phosphorus, sodium), albumin, vitamin D, omega 3 fatty acids, adiponectin, leptin, uric acid); inflammation-mediated and redox biomarkers (rheumatoid factor, CRP, interleukins (IL-6, 8, 10), TNF $\alpha$, HSP72, MIP-1 $\beta$, MIF, b-CHE, oxLDL, carotenoids); muscle protein turnover biomarkers (P3NP, osteonectin, 3MH, creatinine, cystatin C, cathepsin D, S100A8). CAF22, C-terminal agrin fragments 22; T, testosterone; DHEA, dehydroepiandrosterone; $\mathrm{GH}$, growth hormone; IGF1, insulin-like growth factor-1; FST, follistatin; GDF-15, growth differentiation factor 15; TGF $\beta$, transforming growth factor beta; BMPs, bone morphogenic proteins; IR, irisin; BDNF, brain-derived neurotrophic factor; FABP3, fatty acid binding protein 3; C1q, complement component $1 \mathrm{q} ; \mathrm{TNF} \alpha$, tumor necrosis factor $\alpha$; HSP72, heat shock 70 kDa protein 1 ; MIP- $1 \beta$, macrophage inflammatory protein $1 \beta$; MIF, macrophage migration inhibitory factor; b-CHE, butyryl-cholinesterase; oxLDL, oxidized low-density lipoprotein; $\mathrm{P} 3 \mathrm{NP}, \mathrm{N}$-terminal peptide; 3MH, 3-methylhistidine. 


\section{Methodology}

A structured search strategy was conducted in PubMed and Google Scholar to search for publications in English using the search term "sarcopenia" in combination with one of the following keywords: "factors", "epidemiology", "ethnicity", "health status", "quality of life", "symptoms", "functional limitations", "medical history", "comorbidities", "genetic factors", "gut microbiota", "gut microbiome", "psychological factors", "social factors", "psychosocial factors", "behavioral risk factors", "biochemical factors", "biomarkers", "impacts", "social impacts", "individual impacts" and "financial impacts". Furthermore, we also searched each biochemical biomarker mentioned in this review for the most updated related research. We focused on clinical trials, meta-analyses, and review articles. We did not include research related to sarcopenia management. The search was completed on 1 August 2021. When many similar articles were available, the most recent were used. Additional papers were identified from random searches and the reference lists of retrieved articles. No date restriction was put on the search so that a longitudinal "map" of the subject area could be obtained. These approaches resulted in a total of 159 articles for possible inclusion within this review.

\section{Risk Factors for Sarcopenia}

\subsection{Epidemiology of Sarcopenia}

\subsubsection{Region and Gender}

A systematic review of studies revealed sarcopenia (EWGSOP1 criteria) to be prevalent in $1 \%$ (Finland) to $29 \%$ (Italy) of people over 50 years old; $10 \%$ (UK) for acute hospital-care settings, and from $14 \%$ (The Netherlands) to $33 \%$ (Italy) for long-term care institutions [20]. Pooled analysis of nine American studies of people aged 65 and over found that $5.3 \%$ of men and $13.3 \%$ of women had sarcopenia [21]. According to a study of approximately 4000 people residing in the community aged 65 and older in Hong Kong, 9.0\% of subjects had baseline sarcopenia (EWGSOP1 criteria). The prevalence (EWGSOP1 criteria) rates in elderly community-living populations range between $1 \%$ and $29 \%$ and between $14 \%$ and $33 \%$ in long-term care populations [20]. Sarcopenia prevalence (AWGS criteria) in Asia ranges from $2.5 \%$ to $45.7 \%[9,22]$. There are differences in the prevalence of sarcopenia among study populations by countries, by ages, by gender, by settings, and by measurement methods in Asia. The prevalence of sarcopenia in Asian populations varies substantially $[9,23,24]$. The existing Asian studies emanate from Japan, China, Taiwan, Korea, and Thailand.

Based on the current definition of sarcopenia, which also requires low muscle strength or inadequate physical performance, low muscle mass alone has a higher prevalence than the current definition [25]. According to a low muscle mass definition, the prevalence in older Asian adults ranges from $6.7 \%$ to $56.7 \%$ in men and $0.1 \%$ to $33.6 \%$ in women $[9,26]$, while current definitions show $9 \%$ to $22.1 \%$ in men and $7.7 \%$ to $21.8 \%$ in women $[9,27,28]$. A meta-analysis of 58,404 elderly adults (2009-2016) was performed in 2017. According to the estimates, prevalence was $10 \%$ among men and $10 \%$ among women. In both genders, the prevalence was significantly higher among non-Asian individuals than Asians, when muscle mass was measured using BIA ( $20 \%$ compared with $10 \%$ in men; $11 \%$ in women) [29]. The prevalence of sarcopenia was reported to be $8.2 \%$ for men and $6.8 \%$ for women in a population-based cross-sectional study in Japan [30]. An important study in 2020 compared the prevalence of sarcopenia among Chinese community-dwelling older adults ( $n=483$, age $66.8 \pm 4.4$ years) based on all diagnostic criteria present on sarcopenia. The prevalence of EWGSOP2-defined sarcopenia (men: 6.5\%; women: 3.3\%) was lower than that defined by the EWGSOP1 (men: 22.3\%; women: 11.7\%), AWGS (men: 10.9\%; women: $8.0 \%$ ), and IWGS (men: $24.5 \%$; women: $11.0 \%$ ) criteria, but higher than FNIH criteria (men: $6.0 \%$; women: $1.7 \%$ ) [15]. 


\subsubsection{Ethnicity}

There have been very few studies conducted investigating the prevalence of sarcopenia in different ethnicities. The prevalence of sarcopenia in adults (aged 18 and older) was analyzed using data from the National Health and Nutrition Examination Surveys from 1999 to 2004 in a study published in 2018. The prevalence of sarcopenia varies by sex and race or ethnicity: Hispanic ( $26.8 \%$ male, $27.2 \%$ female); non-Hispanic $(\mathrm{NH})$ white ( $15.5 \%$ male, $15.1 \%$ female); NH black ( $8.6 \%$ male, $1.6 \%$ female); and other ( $16.5 \%$ male, $23.2 \%$ female) [31]. Another large-scale study $(n=10,325)$, from Louisiana compared the prevalence rates between whites, blacks, Asians, and Hispanics. In men, the rates of sarcopenia and sarcopenic obesity were $17.6 \%$ and $7.0 \%$, respectively, and in women, the rates were $13.7 \%$ and $2.5 \%$, respectively. The prevalence (AWGS criteria) of sarcopenia in individuals ( $n=4500$, age $\geq 50$ years) from Yunnan, Guizhou, Sichuan, and Xinjiang provinces was reported. The prevalence of sarcopenia was $22.3 \%$ in Han, $18.2 \%$ in Tibetans, $11.8 \%$ in Qiang, $34.7 \%$ in $\mathrm{Yi}$, and $26.7 \%$ in Huis [32].

\subsection{Health Status}

Health status is determined by the effect of disease on patient function, as described by patients through three components including the range of symptoms a patient is experiencing, their functional limits (physical and mental), and the quality of their life, which is defined by the discrepancy between their current and desired level of performance. Range of symptoms includes reduced skeletal muscle mass, reduced strength, and/or diminished physical performance. These are the main reasons older people are restricted in their daily activities, leading to disability, falls, hospitalization, fractures, or death $[9,12,33]$. Symptom-screening questionnaires including "Strength, assistance with walking, rising from a chair, climbing stairs, and falls" (SARC-F) by EWGSOP2 [12] and SARC-F combined with calf circumference (SARC-CalF) by AWGS2 are being used [13]. Handgrip test (to quantify muscle strength), chair stand test (to gauge lower extremity strength), gait speed test (to test $4 \mathrm{~m}$ usual walking speed), short physical performance battery (to test poor physical performance, including chair stand tests, standing balance, and walking speed), timed-up and go test (to indicate physical deficits by observing the time taken for a subject to rise from a chair, walk $3 \mathrm{~m}$ away and $3 \mathrm{~m}$ back to the chair, terminating the test in a sitting position) and the $400 \mathrm{~m}$ walk test (to assess physical inability to walk in a series of $20 \times 20 \mathrm{~m}$ laps as quickly as possible, with a maximum of $2 \mathrm{~min}$ rest between each lap) are among the most common assessment methods used for assessing the symptoms of sarcopenia [33,34].

Apart from screening and assessing symptoms of sarcopenia, functional limits that include both mental and physical limitations are second important components of health status. In 2021, research examined the association between sarcopenia and its components (based on AWGS) with cognitive function (based on the Montreal Cognitive Assessment) in Chinese aging community dwellers ( $n=428$, age $\geq 80$ years). The result revealed that sarcopenia had an overall prevalence of $35.5 \%$, with $40.34 \%$ in men and $32.14 \%$ in women. Mild cognitive impairment was significantly associated with sarcopenia, low handgrip strength, and slow gait speed in community-dwelling elders. The prevalence of mild cognitive impairment was higher among sarcopenic older people than older people without sarcopenia [35]. Another study was conducted in 2020 among Thai communitydwelling older adults ( $n=330$, age $66.85 \pm 5.54$ years, $76.06 \%$ female) to explore the association of sarcopenia (AWGS criteria) with depression, cognitive performance, and physical activity (gait speed, muscle mass, and handgrip strength) reported $16.1 \%$ of participants had sarcopenia. Furthermore, advanced age, high depression scores, mild cognitive impairment, and low physical activity levels were significantly associated with sarcopenia after adjusting for age, sex, and educational level [36].

The third component, which is health-related quality of life (HRQoL), is one of the main factors in determining health status. Recently in 2021, a study was performed to examine the relationship between severity of sarcopenia and HRQoL in community-dwelling 
middle-aged people. They reported the independent association between probable sarcopenia and poor HRQoL, but not with confirmed or severe sarcopenia [37]. Sarcopenia and Quality of Life (SarQoL), a self-administered questionnaire to assess health-related quality of life in sarcopenia, has recently been developed. This questionnaire is valid, consistent, and reliable, which makes it suitable for clinical and research studies [38]. Another study from Belgium $(n=387)$ found that lower QoL was found for sarcopenic subjects compared with non-sarcopenic subjects by using the definitions of Cruz-Jentoft, Studenski, Fielding, and Morley [39]. Another study from the Korean National Health and Nutrition Examination Survey conducted between 2008 and $2011(n=4937$, aged $\geq 60$ years) measured health-related quality of life. They reported that sarcopenia was prevalent in $6.6 \%$ of Korean people (age $\geq 60$ years), $11.1 \%$ in men, and $3.2 \%$ in women. They also concluded that findings differ between men and women but that there is a clear link between sarcopenia and poor health-related quality of life in older Korean populations [40].

\subsection{Medical History/Comorbidities}

A total of 20 of the 21 prognostic outcomes of tumor were found to be associated with sarcopenia in an umbrella review based on 30 meta-analyses. They reported that sarcopenia is significantly associated with adverse health outcomes, especially in the case of cancer patients and elderly populations. Additionally, sarcopenia was also associated with metabolic disorders, depression, and albuminuria [41]. A cross-sectional study conducted in Brazil, ( $n=1078$, age $\geq 60$ years) defined by the EWGSOP, showed that diabetes mellitus (DM) was present in $36.87 \%$ of patients, with a greater incidence among sarcopenic patients. Female sex, advanced age, DM, cardiovascular problems, osteoporosis, BMI, waist circumference, triglycerides, and physical function were all associated with sarcopenia [42]. An analysis of 112 chronic liver disease patients (57 men and 55 women), including 40 cirrhotic patients (36\%), examined the relationship between osteoporosis and sarcopenia. Among the elderly, $13 \%$ had sarcopenia, $17 \%$ had osteoporosis, and $65 \%$ had osteopenia. There was a significant and high incidence of osteoporosis in sarcopenic and cirrhotic patients [43]. In a further study, sarcopenia and obesity were linked to peptic ulcer disease (PUD). In this study, 7092 patients were divided into four categories: sarcopenic obesity (870), sarcopenic overweight (2676), non-sarcopenic overweight (2698), and non-sarcopenic overweight (848). Among these groups, the prevalence of PUD was 7.9\%, 7.4\%, 6.3\%, and $3.8 \%$, respectively. They concluded that increased risk of PUD was determined when muscle mass, fat mass, and obesity were considered together [44].

Furthermore, even neurological diseases need to be considered as an important risk factor. In an observational study, 104 Parkinson's disease patients enrolled in a tertiary center and 330 non-Parkinson's disease controls enrolled in a population-based cohort of individuals 65 years of age. Patients from a tertiary center who had Parkinson's disease had a $55.8 \%$ prevalence of sarcopenia, while non-Parkinson's disease controls had $8.2 \%$ prevalence. The prevalence of sarcopenia in the Parkinson's disease community sample was $33.3 \%$, and frailty was $22.2 \%$. Both frailty and sarcopenia were found to be more common in Parkinson's disease patients than in the general population and predicted a more detrimental outcome for patients [45]. The onset of dementia and sarcopenia was also evaluated using a meta-analysis and reported an increased prevalence of sarcopenia in dementia patients [46]. The study described a 78-year-old man who had a compromised cognitive capacity, waning strength in the lower extremities, and gait difficulties. In addition to sarcopenia and polyneuropathy, he was also diagnosed with Alzheimer's disease. Chronic elevations of inflammatory markers were also detected. Researchers originally thought inflammation with aging, or "inflammaging", contributed to multiple comorbid diseases. A multidisciplinary treatment program and comprehensive rehabilitation allowed him to ambulate again with only little to moderate assistance [47]. In this manner, various age-related disorders should be considered when an elderly patient has chronic low-grade inflammation and sarcopenia. 


\subsection{Genetic Factors}

The genetic causes of sarcopenia are unclear, despite strong evidence that muscle phenotypes are inherited. Studies that use a genetic risk score for predicting sarcopenia risk are even rarer. Since each of the genes has only a small to moderate effect on sarcopenia risk, it is not necessary to identify the individual genes to understand genetic susceptibility. A polygenic model should be used to explain genetic variations in sarcopenia risk. In 2009, a study tested 379,319 eligible single nucleotide polymorphisms (SNPs) by genome-wide association scan (GWAS) in 1000 unrelated US whites and found that two SNPs, rs16892496 and rs7832552, within the thyrotropin-releasing hormone receptor (TRHR) gene were significantly associated with lean body mass (LBM). They also replicated the significant associations in three independent samples: (1) 2955 Chinese unrelated subjects, (2) 1488 unrelated US whites, and (3) 593 nuclear families comprising 1972 US whites. This study concluded that the TRHR gene is as an important gene for LBM variation [48]. In 2012, an overview of the major and representative molecular genetic studies was conducted, which focused on identifying genetic factors for sarcopenia. They reviewed human whole-genome linkage studies, quantitative trait loci mapping in animal models, newly reported GWAS, candidate gene association studies, DNA microarrays, and microRNA studies of skeletal muscle phenotypes such as sarcopenia. In the study, the authors reported that the angiotensin I-converting enzyme I (ACE), myostatin (MSTN), alpha actinin 3 (ACTN3), ciliary neurotrophic factor (CNTF), and vitamin $\mathbf{D}$ receptor (VDR) genes associated with skeletal strength or mass in several studies The MSTN gene explained a large proportion of the variation in skeletal muscle traits, as corroborated by association studies, linkage studies, and expression studies. A possible importance could be attributed to the genes insulin-like growth factor 1 (IGF1) and interleukin-6 (IL-6), supported by evidence of linkage and association studies [49]. Another case control study was conducted on 175 Taiwanese community-dwelling patients with sarcopenia (56 severe sarcopenia, 63 sarcopenia, and 56 pre-sarcopenia) based on AWGS and 327 ageand gender-matched controls. They reported that caveolin-1 (CAV1) may play an important role in the etiology of sarcopenia. They proposed that the A allele of Cav1 G14713A may serve as an pre-indicator for detection of severe sarcopenia and sarcopenia [50]. In 2020, a study using 2207 unrelated Caucasian subjects to assess the associations between lean mass and fat mass and obesity-associated (FTO) gene was performed by GWAS of lean mass index (LMI). They also replicated major findings in two replication samples including 38,292 unrelated Caucasians and 6004 unrelated Caucasians. They reported 29 SNPs in FTO significantly associated with sarcopenia [51]. Additionally, in 2020, another study based on genetic markers attempted to identify patients who were more likely to develop certain conditions or diseases, such as sarcopenia, or to develop joint problems. According to the traditional GWAS methodology, SNPs associated with muscle phenotypes and specific genes were chosen according to their $p$-values for muscle phenotype associations. They found nudix hydrolase 3 (NUDT3) and kruppel-like factor 5 (KLF5) for lean mass and HLA-DQB1 antisense RNA 1 (HLA-DQB1-AS1) associated with hand grip strength as main genes to target for these phenotypes. The associated regulatory SNPs are rs464553, rs1028883, and rs3129753, respectively [52]. Later in 2021, in a subsequent research study, seven candidate gene variants were tested individually and together for their effect on sarcopenia risk. Kompetitive allele-specific PCR was used to genotype single nucleotide polymorphisms in candidate genes. As determined by the EWGSOPs diagnostic criteria, 190 older adults were classified as sarcopenic or nonsarcopenic. Sarcopenia was reported to be associated with methylenetetrahydrofolate reductase (MTHFR), alpha-actinin-3 (ACTN3), and nuclear respiratory factor 2 (NRF2) genotypes. Together, all three polymorphisms described 39\% of the variation in sarcopenia risk inter-individually [53]. To treat muscle wasting diseases such as sarcopenia, researchers extensively studied the functions and structural properties of MSTN (encoded by the MSTN gene). MSTN is the most studied member of the TGF- $\beta$ family and a negative regulator of skeletal muscle growth and development [54]. Another study suggested that the amount of PR domain-containing 16 
(PRDM16) gene could regulate brown adipose tissue, white adipose tissue, and muscle cell metabolism [55]. In 2021, a GWAS meta-analysis of low grip strength in European participants (age $\geq 60$ years) from 22 studies yielding a combined sample of 254,894 individuals was conducted. They revealed that 15 genetic loci including HLA class II histocompatibility antigen-DRB1 beta chain (HLA-DRB1), growth differentiation factor 5 (GDF5), dymeclin (DYM), deleted in lymphocytic leukemia 1 (DLEU1), solute carrier family 39 member 8 (SLC39A8), RN7SK pseudogene 297 (RN7SKP297), chromosome 12 open reading frame 60 (C12orf60), retinoblastoma-binding protein 6 (RBBP6), aldehyde dehydrogenase 1 family member A2 (ALDH1A2), transforming growth factor alpha (TGF $\alpha$ ), zinc finger and BTB domain-containing protein 38 (ZBTB38), BR serine/threonine kinase 1 (BRSK1), amine oxidase copper-containing 1 (AOC1), FTO and zinc finger protein 678 (ZNF678) were associated with the EWGSOP definition of low grip strength and with two additional loci for the FNIH criteria, which uses a more strict cutoffs for muscle weakness. They reported two lead variants (ALDH1A2 and variants near FTO) that were previously not determined to be associated with anthropometric or musculoskeletal phenotypes in GWAS [56]. A very recent study in 2021 used the Gene Expression Omnibus (GEO) profiles of the National Center for Biotechnology Information for exploring associations between mRNA expressions of biomarkers and sarcopenia. They recruited ( $n=408$, age $=$ muscle strength is an important heritable indicator of poor health linked to morbidity and mortality in older people. Procollagen type III N-terminal peptide (P3NP), apelin and high-temperature requirement serine protease $\mathbf{A} 1$ are useful for diagnosis of sarcopenia in the clinical setting [57]. Several studies have been conducted on nematodes Caenorhabditis elegans and zebrafish to reveal the genetic basis of sarcopenia, but we have not examined those genes in this review $[54,58]$.

\subsection{Gut Microbiota}

In older adults, changes in gut flora composition are associated with a progression of disease and frailty. Van Tongeren et al. [59] were the first researchers who reported for the first time that frailty is associated with microbiota composition in the gut. In particular, a decline in the amount of Bacterioides/Prevotella, Lactobacilli, and Faecalibacterium prausnitzii and an increase in the proportion of Atopobium, Ruminococcus, and Enterobacteriacae were reported in subjects with rate-producing bacteria, suggesting that butyrate plays an important role in strengthening the junctions between intestinal cells and in preventing the spread of microbes [60]. In addition, a reduced level of inflammation may contribute to the maintenance of muscle tissue [61]. In the ELDERMET study (established in 2007 to investigate the role of intestinal microbiota as an agent and indicator of health in 161 Irish subjects aged over 65 years), the butyrate-producing bacteria were linked directly to functional capacity and health status in older community-dwelling adults [62]. Another study published in Nature in 2019, analyzed the gut microbiota, metabolic characteristics, and systemic inflammation among older adults with/without physical frailty and sarcopenia (PF\&S). Community dwellers ( $n=35 ; 18$ with PF\&S, and 17 nonPF\&S, age $\geq 65$ years) were enrolled. Their model correctly identified $91.7 \%$ of participants with PF\&S and $87.5 \%$ of controls. PF\&S subjects showed lower circulating levels of threonine and MIP $1 \alpha$ and higher serum concentrations of aspartic acid. Additionally, increased abundance of Ruminococcus and Oscillospira and decreased abundance of Christensenellaceae and Barnesiellaceae compared with controls was reported [63]. In 2020, a review compiled gut microbiota in relation to sarcopenia and also highlighted the relationship between the abundance of specific intestinal bacteria, serum levels of specific inflammatory biomolecules, and metabolic markers, suggesting the existence of an additional pathway through which changes in gut microbiota may impact on PF\&S pathophysiology [63,64]. In research published in 2021, fecal samples of 60 healthy controls and 27 sarcopenic (case and precase) individuals were collected and analyzed. They reported an overall reduction in microbial diversity in case and precase samples. The genera Lachnospira, Roseburia, Fusicantenibacter, Lachnoclostridum, and Eubacterium — known butyrate producers—-were reported 
as significantly less abundant in case and precase subjects, whereas Lactobacillus was reported to be more abundant in case and precase subjects. Analysis of the intestinal microbiota revealed structural and functional changes potentially contributing to skeletal muscle loss and function in sarcopenia [65].

\subsection{Psychosocial Factors}

The importance of psychosocial factors cannot be underestimated. A study demonstrated that self-efficacy, social isolation, fear of falls, resilience, depression, and social networks directly influence sarcopenia, and they indirectly influence sarcopenia through lifestyle factors. [66]. Psychosocial factors play a role in the origin of nutritional deficiency, and research has highlighted that individuals who eat alone [67] or have narrow social networks [68] are more expected to have malnutrition and to suffer from depression. For this reason, to assess nutritional deficiencies among the elderly, a tool called Mini Nutritional Assessment (MNA) was developed that includes psychosocial factors as well as nutritional measures $[69,70]$. According to AWGS2, most studies have found that nutritional and psychosocial factors individually contribute to sarcopenia, but a recent study investigated the effects of both factors simultaneously in 1019 older adults. "Probable sarcopenia (PS)" was characterized by low handgrip strength and reduced physical performance. The psychosocial factors including self-efficacy, fear of falling, social isolation, and social capital were examined. There were 426 men (41.8\%) and 593 women (58.2\%), with mean ages of $72.1 \pm 7.6$ years. A total of $29.8 \%$ of people in the study lived alone, $65.9 \%$ did not have an education beyond middle school, and $85.9 \%$ did not make more than 2 million Korean won salary per month. One aspect of PS in elderly adults is physical performance, which is affected by a variety of psychosocial factors [71]. Self-efficacy is allied with limitations in physical function [72] and gait speed [73]. Self-efficacy is known to mediate the relationship between lifestyle, including physical activity and functional limitations in the elderly, and is an important factor in lifestyle improvement activities such as exercise and nutrition $[74,75]$. Thus, improving physical function requires a cognitive approach aimed at increasing self-efficacy $[76,77]$. Sedentary behavior and physical inactivity are associated with falling fear [78], which deleteriously affects physical functioning among the elderly [79]. In order to reduce a fear of falling, increasing muscle strength and balance will be necessary to improve self-efficacy and promote independence. Sarcopenia, depressive symptoms, and social support were also examined in another study concerning self-efficacy for exercise. Muscle mechanography (MM) was also tested against traditional muscle function and strength tests for convergent validity. The development of greater muscle mass, strength, and function was shown to be associated with a high self-efficacy score, no depressive symptoms, and strong social support. Additionally, all tested measures of muscle function and strength were found to be valid [80]. In older adults, sarcopenia is one of the major causes of disability. In a study, muscle mass, strength, and function and their relationship with depressive symptoms, social support and exercise self-efficacy were examined in 31 residential care apartment complex (RCAC) residents. Interestingly, according to studies of community-dwelling older adults, residents of the RCACs had less muscle mass, strength, and function. It was shown that those who were self-efficacious, without depression symptoms and with powerful social support, had numerically greater muscle mass, strength, and function [81].

\subsection{Behavioral Risk Factors}

Sarcopenia is a condition where muscles lose mass and function as age proceeds due to lifestyle habits that include poor nutrition, physical inactivity, lack of exercise, alcohol consumption, and tobacco use. Sarcopenia is predicted to become more prevalent and costly as life expectancies increase worldwide. We must consider our lifestyle habits in order to delay and treat sarcopenia. Lifestyle factors can reduce the progression of sarcopenia far more than physiological or systemic changes as we age. Thus, educating the public about the importance of an active lifestyle in old age and its effects on skeletal muscle status 
is of great importance in the management of sarcopenia [82]. In Taiwan, 1068 older adults (>65 years) were surveyed via telephone to assess behavioral risk factors. Self-reported daily lifestyle behaviors (such as food intake and exercise) as well as sarcopenia (measured using the SARC-F) and personal characteristics were investigated in this study. Researchers found that older adults who chose unbalanced foods, did not engage in adequate physical activity, and sat for long periods of time had higher risks of sarcopenia. Sleep duration did not show a significant association. They concluded that as far as health behaviors were concerned, a poor diet (six nutrients), not getting enough physical activity (150 min/week), and prolonged sitting ( $\geq 7 \mathrm{~h} /$ day) may lead to sarcopenia in older adults. Interventions for the prevention of sarcopenia should aim to promote a balanced food selection, enough physical activity, and reducing sitting time in older adults [83]. The percentage of European middle-aged and older adults with probable sarcopenia ranged from $4.82 \%$ to $7.40 \%$ based on muscle strength, whereas the percentage of those with sarcopenia was minimal. In general, being older, sedentary, obese, physically inactive, and eating junk food resulted in an elevated risk of having low muscle mass, low muscle strength, or low functional performance-all factors connected with sarcopenia [84]. A decrease in food intake, particularly protein intake, due to lifestyle choices [85], sedentary behavior, physical inactivity, lifelong tobacco use, and alcohol abuse have all been associated with a high risk of sarcopenia [86]. Furthermore, people who spend long periods of time in bed and are immobile lose muscle mass and experience weight loss as they age [87].

\subsection{Biochemical Factors}

A number of complex biochemical interactions account for skeletal muscle changes as we age, including changes to neuromuscular junctions, endocrine systems, growth factors, and muscle protein turnover and metabolic dysregulations. As sarcopenia can be multifactorial in nature and involves many pathways, it is impossible to identify a single biomarker for the disease [88]. Here, we review a number of interesting studies and trials that have evaluated biomarkers associated with people with sarcopenia based on a variety of pathways (Figure 2):

\subsubsection{Neuromuscular Junction (NMJs) Biomarkers}

One of the hallmarks of sarcopenia is the detonation of the NMJ [89]. Some studies suggest that the number of circulating C-terminal agrin fragments (CAF) is significantly higher in the sarcopenic population than in the non-sarcopenic population [90,91]. As an integral component of the neuromuscular junction, agrin aggregates acetylcholine receptors at the postsynaptic terminal. In sarcopenia, and in other catabolic diseases, agrin is cleaved into CAF22 via proteolytic cleavage, causing NMJ dysfunction. CAF22 levels have recently been reported to rise with sarcopenia in patients suffering from pulmonary diseases [92]. Further to this, accelerated sarcopenic patients consistently had higher CAF22 serum levels than did healthy controls. In individual cohorts of participants, serum CAF22 levels were not correlated with SPPB (Short Physical Performance Battery) or SARC-F (questionnaire, a screening tool that can be rapidly implemented by clinicians to identify probable sarcopenic patients, including deficiencies in strength, walking, rising from a chair, climbing stairs, and experiencing falls), two tools that can rapidly identify sarcopenic patients [93].

\subsubsection{Endocrine System Biomarkers}

Testosterone $(\mathrm{T})$ is a steroid hormone produced mainly by the testes, ovaries, and the adrenal cortex, which stimulates the development of secondary sexual characteristics in men. It also synthesizes muscle protein [94]. In a review of the literature, T supplementation was found to reduce the loss of muscle mass and grip strength [95]. While epidemiological studies have shown inconsistent results, lower T levels have been linked to decreased muscle mass and function [96-99]. In a recent study with 396,707 participants $(68.8 \%$ of whom were women, aged 38 to 73 years) with sarcopenia (EWGSOP2 criteria), higher T concentrations were associated with sarcopenia in women only [100]. 
Dehydroepiandrosterone (DHEA) is a hormone produced in the adrenal gland; especially due to its unique age-related effects, this precursor of androgen is often considered a senescence marker. It declines as a result of the loss in muscle mass [101] and strength [102]. Additionally, higher levels of DHEA are linked to fewer falls [103]. Muscle mass is also affected by DHEA [104]. Growth hormone (GH; produced by the pituitary gland located at the base of the brain) concentrations decline gradually with age at the same rate as $\mathrm{T}$, but more importantly, its production drops between 5- and 20-fold below that of young adults after the age of 30 years. Deficiencies in GH result in muscle loss but not in muscle strength. Insulin resistance or insulin deficiency accelerates the development of sarcopenia [105]. IGF-1 is produced by the liver primarily, along with the target tissues in an autocrine and paracrine manner. In a recent cross-sectional study, researchers examined elderly patients $(n=3276)$. A body composition survey, grip strength, and speed measurements were taken. Sarcopenia (AWGS criteria) in the older population was associated with GH and IGF-1. The reduction in skeletal muscle mass was linked to IGF-1, mechanical growth factor, and BMI, as well as gender [106]. The lowest IGF-1 concentrations were linked with sarcopenia in men and women in another large study of 396,707 participants (68.8\% women, ages 38 to 73 years) from the UK Biobank (EWGSOP2 criteria) [100]. In another study, community-dwelling adults from Seoul ( $n=96$, age $\geq 60$ years) were assessed for sarcopenia (AWGS criteria) and reported lower serum IGF-1 levels in sarcopenic patients compared with controls [107].

\subsubsection{Growth Factors Biomarkers}

There is a theory that sarcopenia is caused by an imbalance between growth-enhancing and growth-suppressing factors, favoring the latter. MSTN is produced by myocytes and is released into the body to inhibit muscle cell growth. It is a possible candidate for muscle mass negative regulation. Its expression in sarcopenia may be identified only in satellite cells, rather than throughout all muscles [108]. Despite not being a feasible biomarker in isolation, a recent review concluded that MSTN could be a valuable contributor to a recently suggested panel of muscle wasting biomarkers [109]. Moreover, Laurent et al. [110] in a letter to the editor raised concerns that sarcopenia and frailty often appear together but are separate disorders and asserted that there must be a clearer correlation between MSTN and each condition separately. A second claim has been made that MSTN's influence on circulating versus autocrine/local hormones needs to be better understood [110]. Activin A and B, are members of the transforming growth factors (TGF) $\beta$ superfamily and may have an important role in regulating muscle mass. In cancer-induced cachexia, they are 100 times more effective than MSTN in causing muscle wasting in some mouse models of the disease [111]. Sarcopenia patients, however, have not been investigated extensively. Follistatin (FST) is an autocrine glycoprotein that is expressed in virtually every tissue in higher animals. It inhibits MSTN, activin A, and TGF $\beta$ and consequently enhances muscle progenitor cell-dependent myogenesis [112]. Recent research in 2020, however, concluded that sarcopenic prevalence of $56.4 \%$ was found among patients with hepatocellular carcinoma and that serum FST level was an independent factor for poor survival [113]. GDF-15 is expressed at low levels in many organs but is upregulated by injury to the liver, kidney, heart, and lungs. In patients hospitalized in intensive care, the expression of GDF-15 was associated with a reduction in the expression of some microRNAs that contribute to muscle growth [114]. An analysis of cross-sectional data $(n=929)$ as well as two-year prospective data ( $n=788$, age $70-84$ years) in the Korean Frailty and Aging Cohort Study was conducted recently. The participants at baseline had a sarcopenic condition of $16.6 \%$. Sarcopenia was associated with higher median GDF-15 concentrations than non-sarcopenia patients. After a 2-year follow-up, researchers found elevated GDF-15 linked with widespread sarcopenia, but the prediction of incident sarcopenia could not be made [115]. GDF-15 must be investigated further to understand its pathophysiological effects on sarcopenia. Every lineage of white blood cells produces TGF $\beta$. It has been shown to inhibit myogenesis [116], but it is unclear how it contributes to sarcopenia. Bone 
morphogenic proteins (BMPs) are growth factors also called cytokines and metabologens. A recent study revealed that BMPs directly compete with MSTN/activin/TGF $\beta$ in skeletal muscle, leading to increases in muscle mass [116], although their role in sarcopenia is not fully understood. Irisin (IR) is produced and expressed by adipose tissue and muscle in association with obesity and insulin resistance. It has been investigated in individual cohorts of healthy controls and chronic heart failure and COPD patients $(n=81-87 /$ group, aged 55-74 years); the categories with sarcopenia (EWGSOP criteria) were found to be associated with low levels of IR [93]. Sarcopenia was found in 73 (39\%) of 187 patients with liver cirrhosis in a recent study $(n=187)$. The findings revealed that sarcopenia patients had lower IR concentrations than nonsarcopenic patients [117]. A total of 715 Koreans living in the community were evaluated for anthropometrics, body composition, and sarcopenia-related parameters proposed by the AWGS, as well as serum IR levels. Researchers concluded that low levels of circulating IR are sensitive indicators of muscular weakness and atrophy and could be used to predict sarcopenia and monitor age-related changes in muscle fibers [118]. Sclerostin is a protein secreted by bones (osteocytes), and it inhibits bone growth. In an evaluation of 92 patients on hemodialysis examining the prevalence, levels of chronic sarcopenia, and metabolic parameters associated with the disease, results suggested that hemodialysis patients with diabetes had higher serum sclerostin concentrations and that these were inversely correlated with muscle mass [119]. BDNF is a neurotrophic factor that helps neurons develop, mature, and survive, and it shows a neuroprotective effect in adverse environments. In a retrospective cross-sectional study, Japanese patients ( $n=20$, aged $>65$ years) who were undergoing maintenance hemodialysis over 6 months were assessed. The study concluded that BDNF deficiency can result in decreased physical performance and a higher likelihood of severe sarcopenia and frailty among Japanese maintenance hemodialysis patients. Loss of BDNF reduces the motor end plate volume without affecting the integrity of the NMJ. Slowing muscle function and increasing resistance to fatigue caused by contractions are associated with these morphological changes. On the other hand, BDNF overexpression promotes the expression of fast muscle-type genes and increases the number of glycolytic fibers. Based on these findings, BDNF appears to be important for fiber type specification and may be a therapeutic target for diseases of the muscle [120]. Fatty acid binding protein 3 (FABP3) participates in lipid transport, storage, signal transduction, oxidation, and transcriptional regulation. A group of male healthy controls and patients with chronic heart failure and chronic obstructive pulmonary disease ( $n=81-87$ per group, aged 55-74 years) were identified for sarcopenia (EWGSOP criteria). The study concluded that healthy controls, chronic heart failure patients, and COPD patients with sarcopenia status had higher levels of FABP3 in their individual cohorts [93]. Aldolase A is a glycolytic enzyme that catalyzes fructose-1,6-bisphosphate to glyceraldehyde-3-phosphate and dihydroxyacetone phosphate. Studying aldolase A levels with MS spectrometry analysis, researchers found that a sarcopenia group had 4.2-fold higher levels than the control group. ELISA and Western blotting did not detect differential expression of full-length aldolase A, but fragments of the protein were detected as being differentially expressed [121]. Sex hormone-binding globulin is a glycoprotein involved in binding androgens and estrogens. A recent UK Biobank study $(n=396,707)$ reported higher sex hormone-binding globulin concentrations in both men and women with higher sarcopenia (EWGSOP2 criteria) and even found an association [100].

\subsubsection{Muscle Protein Turnover Biomarkers}

N-terminal peptide (P3NP) is the amino terminal peptide of type III procollagen, and it is released when type III collagen is synthesized and deposited. In a study, researchers recruited healthy male controls as well as people with chronic heart failure and chronic obstructive pulmonary disease ( $n=81-87$ /group), aged 55-74 years based on EWGOS. They reported that sarcopenia status was associated with higher levels of P3NP and osteonectin (glycoprotein binds calcium to bone) in the individual cohorts of healthy controls, chronic heart failure, and chronic obstructive pulmonary disease patients [93]. In a further study, 
community-dwelling adults from Seoul ( $n=96$, age $\geq 60$ years) were recruited. Sarcopenia was identified based on AWGS. Higher serum osteonectin levels in sarcopenic patients were reported compared with controls [107]. The amino acid 3-methylhistidine (3MH) is found in actin and myosin. In a cross-sectional study of community-dwelling individuals (>65 years of age), plasma 3MH, 3MH/creatinine, and 3MH/estimated glomerular filtration rate were correlated with frailty status. In the context of the FRAILOMIC initiative, 360 participants from two French cohorts were categorized into robust, pre-frail, and frail using Fried's frailty criteria. According to their research, $3 \mathrm{MH}, 3 \mathrm{MH} /$ creatinine, and $3 \mathrm{MH}$ /estimated glomerular filtration rate in plasma may be useful biomarkers for identifying frail individuals or those at higher risk of becoming frail [122]. There is still a need for further research, especially longitudinal research. Creatinine is a waste product formed by the normal wear and tear of muscles. Researchers from a study with 396,707 participants (68.8\% women, ages 38 to 73 ) from the UK Biobank reported that sarcopenia was associated with, respectively, lower creatinine levels and higher cystatin $\mathbf{C}$ (the kidneys filter cystatin $\mathrm{C}$ from the blood and break it down at a constant rate) levels [100]. Cathepsin D is a ubiquitous lysosomal aspartic endo-protease. An immunoassay study found that the level of cathepsin D in the serum of patients with sarcopenia was higher than in normal people. Gait speed and cathepsin D levels in serum showed an inverse relationship. In order to improve diagnostic performance, a predictive model including cathepsin D, age, and BMI was developed (AUC $=0.908$ ) [123]. According to EWGSOP1, 19 sarcopenic subjects and 20 controls were selected based on age, gender, and sarcopenia. Their MS analysis revealed that the sarcopenia group showed 2-fold higher cathepsin D levels and 4.2-fold higher S100A8 levels than the control group. S100A8 are calcium- and zinc-binding proteins that regulate inflammation and immunity. Moreover, Western blot tests showed that sarcopenia patients had an enhanced detection of S100A8 [121].

\subsubsection{Behavior-Mediated Pathways Biomarkers}

A variety of behavioral factors contribute to sarcopenia, including eating habits, obesity, and physical activity levels. Sarcopenia is well known to be associated with low physical activity and aging-induced increases in complement component 1q (C1q), which is involved in the complement system, a part of the innate immune system. A crosssectional study analyzed the effect of serum C1q level on muscle mass and strength in 131 healthy participants, aged 20-81 years. A cross-sectional study found that serum C1q levels increased with aging and were negatively related to muscle density and strength. In this regard, $\mathrm{C} 1 \mathrm{q}$ may be a novel indicator of sarcopenia, as it reflects the loss of muscle mass [124]. Hemoglobin transports oxygen through the blood. In a longitudinal aging study, 730 participants' data were assessed for sarcopenia (AWGS2 criteria) and anemia (WHO criteria). The study found that $16.2 \%$ of patients were anemic, and $8.5 \%$ were sarcopenic. The higher the hemoglobin level, the faster the gait and the stronger the grip were observed. A high level of anemia was significantly linked with sarcopenia, slowness, and weakness. In men and those with a high disease burden, anemia and sarcopenia appeared to correlate more strongly. The authors concluded that anemia was found to be a risk factor for sarcopenia in older adults [125]. Regarding minerals, the prevalence of sarcopenia and/or the role of dietary mineral intake or mineral serum concentration was reviewed in a systematic review conducted in 2016 on healthy or frail older adults (average age $\geq 65$ years). The results showed that serum calcium intake and selenium were significantly associated with muscle mass and that selenium, magnesium, zinc, and iron intake were positively associated with physical performance in the elderly. Furthermore, selenium, magnesium, calcium, and phosphorus intake were correlated with the prevalence of sarcopenia. The analysis concluded that magnesium, selenium, and calcium seem to be the most promising biomarkers based on observational studies [126]. Albumin is the most abundant circulating globular protein found in plasma. A study with total of 396,707 (68.8\% women, age 38 to 73 years) participants from UK Biobank (EWGSOP2 criteria), reported that higher concentrations of albumin and sodium were 
associated with sarcopenia in both men and women, whereas lower values of vitamin D (fat-soluble secosteroids that increase intestinal absorption of calcium, magnesium, and phosphate) were associated with sarcopenia only in men [100]. Only a few studies specifically analyzed vitamin D status, sarcopenia, and functional performance of the oldest-old (above 85 years) [127]. There is a need for further research on the effects of vitamin D on muscle and skeletal health among adults in this age group [128]. Clinical trials have investigated the association between selenium, magnesium, and omega 3 fatty acids (polyunsaturated fatty acids) with physical activity and muscle performance in elderly individuals taking the supplements and consuming the foods containing these nutrients. Observation of the Mediterranean diet and higher intake of fruits and vegetables has been associated with better physical performance and protection from sarcopenia, muscle wasting, and the onset of frailty [129]. Adiponectin performs anti-inflammatory, anti-fibrotic, and antioxidant effects through its secretion by adipocytes. Researchers reported that sarcopenic participants had adiponectin levels that were significantly higher than those of their controls in a meta-analysis of seven studies. Sarcopenic individuals (AWGS criteria) were reported to have higher adiponectin levels in subgroup analyses in Asians, with a significant influence of female gender [130]. Leptin is predominantly produced by adipocytes and enterocytes in the small intestine; it regulates energy balance by suppressing hunger, which then reduces fat storage in adipocytes. In a study, 4063 older adults aged 60 years and over were enrolled from the NHANES III database. The study found that SMI and BMI were negatively correlated with serum leptin levels [131]. Higher handgrip strength was associated with higher plasma uric acid concentrations in older men and women [132]. Among 396,707 (68.8\% women, ages 38 to 73 years) participants in the UK Biobank, sarcopenia was associated with urea, but only among women [100].

\subsubsection{Inflammation-Mediated and Redox Pathways Biomarkers}

In 2020, a systematic review and meta-analysis was published for exploring the association between inflammation markers and muscle mass and strength. Overall, 168 articles, $n=89,194$, were included. Higher levels of C-reactive protein (CRP), tumor necrosis factor (TNF) $\alpha$, and IL-6 were associated with knee extension strength, muscle and lower handgrip strength, and muscle mass. A higher level of systemic inflammatory markers was associated with a decrease in muscle strength and mass over time [133]. Below we have compiled the studies that have investigated inflammatory/redox pathway biomarkers in association with sarcopenia. Rheumatoid factor is an immune system protein that may attack healthy cells in the body. A total of 240 Japanese patients with rheumatoid arthritis aged 65 years and older were studied according to AWGS criteria. Researchers found that patients with rheumatoid arthritis were more likely to suffer from sarcopenia based on age, BMI, C-reactive protein, and hip bone density [134]. Additionally, a study with a total of 396,707 (68.8\% women, age 38 to 73 years) participants from UK Biobank defined by EWGSOP2 criteria reported that higher concentrations of rheumatoid factor and CRP is produced by the liver and increases during inflammation. CRP has been found to be associated with sarcopenia in both men and women [100]. Interleukins (IL) are a group of cytokines. In 2017, 17 studies with a total of 11,249 participants (3072 with sarcopenia and 8177 without) were meta-analyzed [135]. The authors noted no significant difference between sarcopenia patients and controls regarding serum IL-6 levels. IL-6 functions both as an anti-inflammatory myokine and a pro-inflammatory cytokine. A further study, however, showed that patients with obesity and diabetes who develop sarcopenic obesity as they age have persistent and markedly elevated levels of pro-inflammatory cytokines such as IL-6 [136], indicating subtle relationships between endocrine and metabolic phenomena and inflammatory aging. Chronic low-grade inflammation caused by IL-6 is a major cause of sarcopenia and part of the aging process. The activity of IL-6 during physiological conditions is limited by the duration of the injury, but the signaling of IL-6 causes chronic low-grade inflammation [137]. Further research on community-dwelling adults from Seoul ( $n=96$, age $\geq 60$ years) was conducted. Sarcopenia was identified based 
on AWGS. They reported higher serum IL-6 levels in sarcopenic patients as compared with control [107]. The same meta-analysis found that sarcopenic patients' TNF $\alpha$ (which is the cell-signaling protein of the immune system) levels were not higher than their control counterparts. According to the results, sarcopenia may be associated with elevated blood CRP levels; further studies are needed to clarify the link [135]. Heat shock 70 kDa protein $\mathbf{1}$ (HSP72) is a protein that under stressful conditions facilitates the folding of newly synthesized proteins, facilitates the translocation of precursor proteins into organelles, and helps in the degradation of damaged proteins. Researchers tested plasma levels of HSP72, serum CRP, IL-6, TNF $\alpha$, and other biomedical parameters in blood samples from both men and women $(n=665)$. Having higher Hsp72 levels in the plasma may be a useful biomarker of sarcopenia in the elderly since it was associated with lower muscle mass, weak grip strength, and slower walking speed [138]. As part of the study on biomarkers associated with sarcopenia and physical frailty in elderly people, 200 community dwellers, 100 with physical frailty and sarcopenia and 100 without the condition were recruited. Among 74 biomarkers of frailty and sarcopenia, aspartic acid and HSP72 showed higher levels in serum, and macrophage inflammatory protein $\mathbf{1} \beta$ (MIP-1 $\beta$ ) (a chemoattractant, as well as a neutrophil stimulator) had lower levels, with peculiar gender differences [139]. Macrophage migration inhibitory factor (MIF) is a key regulator of innate immunity that is found in virtually all cells. Males aged 55 to 74 years from healthy controls and patients with chronic heart failure and chronic obstructive pulmonary disease ( $n=81-87$ /group) were recruited to participate in a study. Using the EWGOS recommendations, sarcopenia was clinically diagnosed. The MIF levels were higher in healthy controls as well as in chronic heart failure and chronic obstructive pulmonary disease patients who were classified as having sarcopenia (SPPB score of 8 or SARC-F score of 4) in general [93]. Higher serum MIF levels in sarcopenic patients were also reported compared with controls among community-dwelling adults from Seoul ( $n=96$, age $\geq 60$ years) based on AWGS [107].

Another observational study indicated an association between chemotherapy-induced sarcopenia and the inflammatory markers HsCRP, IL-8, and TNF- $\alpha$. In patients newly diagnosed with non-metastatic cancer, chemotherapy-induced sarcopenia may be exacerbated by inflammation [64,140]. IL-10 is an anti-inflammatory, immunomodulatory cytokine responsible for regulating mucosal inflammation. IL-10-null mice, a rodent model of chronic inflammation and frailty with severe mitochondrial damage, were shown to have abnormal autophagosome formation in their skeletal muscle [141]. Inflammation is likely connected with muscle decline by mitochondrial DNA released from damaged organelles, which circulates in the bloodstream [85]. According to a study recently published, mitochondrial dysfunction contributes to sarcopenia's pathogenetic mechanisms [142]. Butyryl-cholinesterase (b-CHE) enzyme is synthesized in the liver and hydrolyzes many different choline-based esters. A study demonstrated that b-CHE levels, which are routine markers of chronic inflammation and malnutrition, are linearly related to grip strength and muscular mass among elderly people. A total of 337 elderly subjects (mean age: $76.2 \pm 6.7$ years) were recruited for comprehensive geriatric assessment, and the study reported that $b-\mathrm{CHE}$ levels were lower in sarcopenic than in nonsarcopenic elderly subjects. Both men and women were found to have linear correlations between $b-\mathrm{CHE}$ and grip strength and muscular mass using linear regression analysis [143]. Oxidized lowdensity lipoprotein (oxLDL) promotes inflammatory processes and foam cell formation and is associated with atherosclerosis. A study included 65 women (age $67 \pm 7$ years) and 9 men (age $71 \pm 8$ years) from a rural village in Japan. Multiple linear regression analysis showed that changes in high-density lipoprotein and malondialdehyde-modified low-density lipoprotein (MDA-LDL/LDL-C) ratio were significantly and independently associated with changes in hand grip strength. Furthermore, in data stratified by gender, change in the MDA-LDL/LDL-C ratio was significantly and similarly associated with change in hand grip strength in women only [144]. Carotenoids are molecules that quench singlet oxygen and neutralize free radicals. A recent study of older people in the community demonstrated that low serum/plasma carotenoids are linked to decrease skeletal 
muscle strength as well as reduced walking ability. It is well known that a diet high in fruits and vegetables reduces inflammation, hypertension, diabetes, cardiovascular disease, and premature death. These observations agree with numerous studies that demonstrate this relationship [145]. In the Women's Health and Aging Studies, 669 community-dwelling adults aged 70 to 79 years with no disabilities underwent cross-sectional analyses. Strength measures related independently to higher amounts of carotenoid and alpha-tocopherol. The findings were consistent with the hypothesis that oxidative stress causes sarcopenia in elderly individuals, but further longitudinal and interventional studies must be conducted to establish causality [146].

\section{Impact of Sarcopenia}

\subsection{Impact at the Individual Level}

Sarcopenia is characterized by decreased mobility, reduced muscle performance, and impaired metabolic health. Furthermore, sarcopenia is related to decreased locomotion ability, resting energy expenditure, nonstructural free-living physical activity, and increased fat mass, all of which have been linked to obesity and metabolic disorders. After the fifth decade of life, there appears to be an accelerated decline in muscle fiber size and number. Muscle loss is mild before age 50 years $(<10 \%)$, but it increases to $30-40 \%$ between the age of 50 and 80 years [147]. Sarcopenia affects many aspects of one's life, including disability and debilitating health problems such as osteoporosis, dyslipidemia, cardiovascular disease, metabolic syndrome, and immunosuppression [148]. The death rate for sarcopenic patients is 4 times higher than for non-sarcopenics. No significant difference in the results was seen depending on the setting of the participants (community-dwelling versus hospitalized subjects versus nursing home residents) or the length of follow-up. Age only influenced the results; as expected, subjects over the age of 79 years were more likely to be affected by sarcopenia. One recent meta-analysis attempted to determine the association between sarcopenia and mortality; however, the authors focused on specific definitions of sarcopenia and excluded studies that used muscle mass as the sole measure [149]. However, they also found that sarcopenic subjects had a higher mortality rate than non-sarcopenic subjects, with a hazard ratio of 1.87 [150].

\subsection{Impact at the Social Level during the COVID-19 Pandemic}

All aspects of society have been impacted by the COVID-19 pandemic, and this will continue to occur. Physical inactivity, a disruption in eating habits, stress, and irregular sleep patterns may put older people at greater risk of sarcopenia, which is associated with diminished overall quality of life and reduced mobility, as well as the development of several lifestyle-related diseases. Many individuals hospitalized by COVID-19 will also suffer from some degree of muscle weakness requiring some form of rehabilitation to recover lost strength and function [151]. Sarcopenia does not yet have a consensus operational definition. Public health outcomes related to this age-related condition include falls, fractures, hospitalizations, institutionalization, and mortality, among others. Consequently, these consequences directly increase personal, social, and health care system costs and will likely continue to do so as the population ages. Exercise programs that focus on improving muscle mass and function may be vital in reducing sarcopenia. In a systematic review published in 2019, de Mello et al. examined the effects of physical exercise programs versus no exercise intervention on sarcopenia features and its determinants in sarcopenic elders [152]. The aim of this study was to evaluate the effect of a six-month home-based resistance-training program on muscle health and physical performance in healthy older subjects during the unique condition of home confinement caused by the COVID-19 pandemic. The home-based resistance-training program during the lockdown period, caused by the COVID-19 outbreak, determined only within-group improvement in lower limb muscle strength but not in muscle mass and composition in older subjects [153]. In recent years, many older people have been affected by sarcopenia and its associated disabilities and that has created a medical and social challenge to develop effective and 
accessible preventive interventions $[25,154]$. Hence, there is a role for smart technologies and devices to promote remote coaching models during coronavirus pandemic because they may have the potential to provide an affordable alternative to coach-based exercise prescription. Exercising using a smartphone application improved cardiorespiratory fitness, body composition, cholesterol profiles, and psychological outcomes in people living with HIV in a 16-week protocol consisting of moderate physical activity three times per week, which included an initial coach-supervised period of 4 weeks, followed by 12 weeks in which participants trained independently [155].

\subsection{Impact at the Financial Level}

Patients with sarcopenia have higher levels of comorbidity, which results in higher costs. According to research, sarcopenia is independently linked to higher costs in the hospital environment. Patients with this condition are required to pay an additional $52.7 \%$ in hospitalization costs (58.5\% for those over 65 and 34\% for those older than 65 years). In total, 656 hospitalized patients aged $\geq 18$ years ( $24.2 \%$ sarcopenic) were included in the study. The costs of hospitalization for patients aged $<65$ years increased by EUR 1240 (95\% confidence interval (CI): EUR 596-1887), while increased costs of EUR 721 (95\% CI: EUR 13-1429) were observed for those aged $\geq 65$ years [156]. An increase in disabilityrelated hospitalizations and nursing home placement, as well as higher household healthcare expenses, is associated with increased health care costs. Since sarcopenia increases disability costs, sarcopenia is expected to lead to high public health costs. At present, there are very few economic data available on sarcopenia. Economic data on sarcopenia are currently very limited. There has only ever been one study on the healthcare costs related to sarcopenia in the United States [5]. As a result of these estimates, the direct costs of sarcopenia reached USD 18.5 billion in 2000, USD 10.8 billion for men, and USD 7.7 billion for women. As a result, hospitalization, nursing home admissions, and home healthcare expenditures contribute to these costs. Approximately $1.5 \%$ of total health spending in the United States was devoted to this area in 2000. Additionally, sarcopenia is associated with multiple comorbid conditions, such as osteoporosis, obesity, and type II diabetes. Sarcopenia may bring even greater economic burden than reported in the Janssen study when these comorbidities and costs of healthcare are considered. There has yet to be a comprehensive economic assessment of sarcopenia in Europe, and the Janssen study is the first of its kind. Despite the lack of other economic assessments, many studies have been conducted regarding the relationships between sarcopenia and the costs of hospitalization and nursing home admission. One study conducted in the United Kingdom showed that sarcopenic patients had significantly longer hospital stays than patients without sarcopenia (mean of $13.4 \pm 8.8$ days for sarcopenic subjects versus $9.4 \pm 7.0$ days for non-sarcopenic subjects; $p=0.003$ ). Sarcopenia is associated with a loss of productivity, a decline in quality of life, and a loss of autonomy. Sarcopenia's indirect costs, however, have not been assessed, either in the United States or in Europe. Janssen et al. [5] investigated how pharmacological treatment, public health campaigns, and physical activity interventions could reduce the prevalence of sarcopenia in the United States, as well as its effect on healthcare spending overall. According to their findings, a 10\% reduction in sarcopenia prevalence would result in a USD 1.1 billion (dollars adjusted to 2000 rate) annual saving in the US. It is important to consider this potential economic savings in public health contexts. It is startling to find that there are no public health campaigns for reducing the prevalence of sarcopenia, despite the economic costs of osteoporotic fractures being similar. Health policy decision-makers should consider economic investments in sarcopenia prevention and treatment to ensure significant savings in the future, especially in light of the growing number of older people worldwide [25]. 


\section{Conclusions}

Even though we encountered differences between studies from different regions of the world regarding the methods used to measure muscle mass and to estimate sarcopenia parameters, we found that sarcopenia is a common disorder among elderly people regardless of sex, ethnicity, or region. The onset of sarcopenia is still related to aging; a timely diagnosis may help to prevent some negative health effects. Identifying the pathogenesis of sarcopenia is the main objective of a modern approach to understanding this intriguing condition. As sarcopenia is a multifactorial condition, it is crucial to emphasize the relevance of the diverse risk factors that contribute to it. In this review, we summarized 13 relevant factors related to this pathogenesis that should be considered before designing any research related to sarcopenia. We suggest that for developing a uniform consensus for screening of this disease we need to focus on the biology of sarcopenia. We found 50 biochemical markers from six pathways that have already been explored in subjects with sarcopenia. Therefore, we suggest that these summarized biomarkers should be evaluated further for future diagnosis to help determine the biology of this disease, thereby contributing to further investigations. This may also help to establish a uniform consensus for screening and defining this disease. Associated with a series of adverse economic and social implications such as disability, hospitalization, and death, sarcopenia is a disease of the elderly characterized by the loss of both muscle mass and strength; as a result, the condition is associated with an increased cost of medical care. We suggest an urgent need for the development of strategies, including exercise, to delay sarcopenia prevalence by utilizing smart technologies in the COVID-19 era.

Author Contributions: R.S., K.P.S., and J.S.B. wrote the manuscript; R.S. and K.P.S. performed the literature search; Y.G., F.L., F.D., and J.S.B. contributed to discussion and editing. All authors have read and agreed to the published version of the manuscript.

Funding: This research received no external funding.

Institutional Review Board Statement: Not applicable.

Informed Consent Statement: Not applicable.

Data Availability Statement: Not applicable.

Acknowledgments: The authors acknowledge the Hong Kong Research Grants Council Postdoctoral Fellowship Scheme (PDFS2021-2H01).

Conflicts of Interest: The authors declare no conflict of interest.

$\begin{array}{ll}\text { Abbreviations } \\ \text { EWGSOP } & \text { European Working Group on Sarcopenia for Older People } \\ \text { IWGA } & \text { International Working Group on Sarcopenia } \\ \text { AWGS } & \text { Asian Working Group for Sarcopenia } \\ \text { FINH } & \text { Foundation for the National Institutes of Health } \\ \text { BIA } & \text { Bioimpedance analysis } \\ \text { SARC-F } & \text { Strength, assistance with walking, rising from a chair, climbing stairs, and falls } \\ \text { HRQoL } & \text { Health-related quality of life } \\ \text { SarQoL } & \text { Sarcopenia and Quality of Life } \\ \text { COPD } & \text { Chronic obstructive pulmonary disease } \\ \text { PUD } & \text { Peptic ulcer disease } \\ \text { KNHANES } & \text { Korean National Health and Nutrition Examination Survey } \\ \text { SNPs } & \text { Single nucleotide polymorphisms } \\ \text { GWAS } & \text { Genome-wide association scan } \\ \text { TRHR } & \text { Thyrotropin-releasing hormone receptor } \\ \text { LBM } & \text { Lean body mass } \\ \text { ACE } & \text { Angiotensin I-converting enzyme I } \\ \text { MSTN } & \text { Myostatin }\end{array}$




\begin{tabular}{|c|c|}
\hline ACTN3 & Alpha actinin 3 \\
\hline CNTF & Ciliary neurotrophic factor \\
\hline VDR & Vitamin D receptor \\
\hline IGF1 & Insulin-like growth factor 1 \\
\hline IL-6 & Interleukin-6 \\
\hline CAV1 & Caveolin-1 \\
\hline FTO & Fat mass and obesity-associated \\
\hline LMI & Lean mass index \\
\hline NUDT3 & Nudix hydrolase 3 \\
\hline KLF5 & Kruppel-like Factor 5 \\
\hline HLA-DQB1-AS1 & HLA-DQB1 antisense RNA 1 \\
\hline MTHFR & Methylenetetrahydrofolate reductase \\
\hline ACTN3 & Alpha-actinin-3 \\
\hline NRF2 & Nuclear respiratory factor 2 \\
\hline HLA-DRB1 & HLA class II histocompatibility antigen-DRB1 beta chain \\
\hline GDF5 & Growth differentiation factor 5 \\
\hline DYM & Dymeclin \\
\hline DLEU1 & Deleted in lymphocytic leukemia 1 \\
\hline SLC39A8 & Solute carrier family 39 member 8 \\
\hline RN7SKP297 & RN7SK pseudogene 297 \\
\hline C12orf60 & Chromosome 12 open reading frame 60 \\
\hline RBBP6 & Retinoblastoma-binding protein 6 \\
\hline ALDH1A2 & Aldehyde dehydrogenase 1 family member A2 \\
\hline TGF $\alpha$ & Transforming growth factor alpha \\
\hline ZBTB38 & Zinc finger and BTB domain-containing protein 38 \\
\hline BRSK1 & BR serine/threonine kinase 1 \\
\hline AOC1 & Amine oxidase copper-containing 1 \\
\hline ZNF678 & Zinc finger protein 678 \\
\hline GEO & Gene Expression Omnibus \\
\hline P3NP & Procollagen type III N-terminal peptide \\
\hline HtrA1 & High temperature requirement serine protease A1 \\
\hline PF\&S & Physical frailty and sarcopenia \\
\hline MNA & Mini Nutritional Assessment \\
\hline PS & Possible sarcopenia \\
\hline MM & Muscle mechanography \\
\hline $\mathrm{RCAC}$ & Residential care apartment complex \\
\hline CAF & C-terminal agrin fragments \\
\hline NMJs & Neuromuscular junction \\
\hline SPPB & Short Physical Performance Battery \\
\hline DHEA & Dehydroepiandrosterone \\
\hline TGF & Transforming growth factors \\
\hline FST & Follistatin \\
\hline GDF-15 & Growth differentiation factor 15 \\
\hline BMPs & Bone morphogenic proteins \\
\hline IR & Irisin \\
\hline BDNF & Brain-derived neurotrophic factor \\
\hline FABP3 & Fatty acid-binding protein 3 \\
\hline P3NP & N-terminal peptide \\
\hline $3 \mathrm{MH}$ & 3-methylhistidine \\
\hline $\mathrm{C} 1 \mathrm{q}$ & Complement component $1 \mathrm{q}$ \\
\hline CRP & C-reactive protein \\
\hline TNF & Tumor necrosis factor \\
\hline IL & Interleukin \\
\hline HSP72 & Heat shock 70 kDa protein 1 \\
\hline MIP-1 $\beta$ & Macrophage inflammatory protein $1 \beta$ \\
\hline MIF & Macrophage migration inhibitory factor \\
\hline $\mathrm{b}-\mathrm{CHE}$ & Butyryl-cholinesterase \\
\hline oxLDL & Oxidized low-density lipoprotein \\
\hline
\end{tabular}




\section{References}

1. Goodpaster, B.H.; Park, S.W.; Harris, T.B.; Kritchevsky, S.B.; Nevitt, M.; Schwartz, A.V.; Simonsick, E.M.; Tylavsky, F.A.; Visser, M.; Newman, A.B. The Loss of Skeletal Muscle Strength, Mass, and Quality in Older Adults: The Health, Aging and Body Composition Study. J. Gerontol. Ser. A Biol. Sci. Med. Sci. 2006, 61, 1059-1064. [CrossRef] [PubMed]

2. Delmonico, M.J.; Harris, T.B.; Lee, J.-S.; Visser, M.; Nevitt, M.; Kritchevsky, S.B.; Tylavsky, F.A.; Newman, A.B. Alternative Definitions of Sarcopenia, Lower Extremity Performance, and Functional Impairment with Aging in Older Men and Women. J. Am. Geriatr. Soc. 2007, 55, 769-774. [CrossRef]

3. Morley, J.E. Sarcopenia: Diagnosis and treatment. J. Nutr. Health Aging 2008, 12, 452-456. [CrossRef]

4. World Health Organization. Ageing and Life Course. 2009. Available online: www.who.int/ageing/projects/elder_abuse/en/ (accessed on 12 September 2021).

5. Janssen, I.; Shepard, D.S.; Katzmarzyk, P.T.; Roubenoff, R. The Healthcare Costs of Sarcopenia in the United States. J. Am. Geriatr. Soc. 2004, 52, 80-85. [CrossRef]

6. Gale, C.R.; Martyn, C.N.; Cooper, C.; Sayer, A.A. Grip strength, body composition, and mortality. Int. J. Epidemiol. 2007, 36, 228-235. [CrossRef] [PubMed]

7. Cruz-Jentoft, A.J.; Baeyens, J.P.; Bauer, J.M.; Boirie, Y.; Cederholm, T.; Landi, F.; Martin, F.C.; Michel, J.-P.; Rolland, Y.; Schneider, S.M.; et al. Sarcopenia: European consensus on definition and diagnosis: Report of the European Working Group on Sarcopenia in Older People. Age Ageing 2010, 39, 412-423. [CrossRef] [PubMed]

8. Fielding, R.A.; Vellas, B.; Evans, W.J.; Bhasin, S.; Morley, J.E.; Newman, A.B.; van Kan, G.A.; Andrieu, S.; Bauer, J.; Breuille, D.; et al. Sarcopenia: An Undiagnosed Condition in Older Adults. Current Consensus Definition: Prevalence, Etiology, and Consequences. International Working Group on Sarcopenia. J. Am. Med. Dir. Assoc. 2011, 12, 249-256. [CrossRef]

9. Chen, L.-K.; Liu, L.-K.; Woo, J.; Assantachai, P.; Auyeung, T.-W.; Bahyah, K.S.; Chou, M.-Y.; Chen, L.-Y.; Hsu, P.-S.; Krairit, O.; et al. Sarcopenia in Asia: Consensus Report of the Asian Working Group for Sarcopenia. J. Am. Med. Dir. Assoc. 2014, 15, 95-101. [CrossRef]

10. McLean, R.R.; Shardell, M.D.; Alley, D.E.; Cawthon, P.M.; Fragala, M.S.; Harris, T.B.; Kenny, A.M.; Peters, K.W.; Ferrucci, L.; Guralnik, J.M.; et al. Criteria for Clinically Relevant Weakness and Low Lean Mass and Their Longitudinal Association With Incident Mobility Impairment and Mortality: The Foundation for the National Institutes of Health (FNIH) Sarcopenia Project. J. Gerontol. Ser. A 2014, 69, 576-583. [CrossRef]

11. Studenski, S.A.; Peters, K.W.; Alley, D.E.; Cawthon, P.M.; McLean, R.R.; Harris, T.B.; Ferrucci, L.; Guralnik, J.M.; Fragala, M.S.; Kenny, A.M.; et al. The FNIH Sarcopenia Project: Rationale, Study Description, Conference Recommendations, and Final Estimates. J. Gerontol. Ser. A 2014, 69, 547-558. [CrossRef]

12. Cruz-Jentoft, A.J.; Bahat, G.; Bauer, J.; Boirie, Y.; Bruyère, O.; Cederholm, T.; Cooper, C.; Landi, F.; Rolland, Y.; Sayer, A.A.; et al. Sarcopenia: Revised European consensus on definition and diagnosis. Age Ageing 2019, 48, 16-31. [CrossRef]

13. Chen, L.-K.; Woo, J.; Assantachai, P.; Auyeung, T.-W.; Chou, M.-Y.; Iijima, K.; Jang, H.C.; Kang, L.; Kim, M.; Kim, S.; et al. Asian Working Group for Sarcopenia: 2019 Consensus Update on Sarcopenia Diagnosis and Treatment. J. Am. Med. Dir. Assoc. 2020, 21, 300-307.e2. [CrossRef]

14. Lee, W.-J.; Liu, L.-K.; Peng, L.-N.; Lin, M.-H.; Chen, L.-K. Comparisons of Sarcopenia Defined by IWGS and EWGSOP Criteria Among Older People: Results From the I-Lan Longitudinal Aging Study. J. Am. Med. Dir. Assoc. 2013, 14, 528.e1-528.e7. [CrossRef] [PubMed]

15. Yang, L.; Yao, X.; Shen, J.; Sun, G.; Sun, Q.; Tian, X.; Li, X.; Li, X.; Ye, L.; Zhang, Z.; et al. Comparison of revised EWGSOP criteria and four other diagnostic criteria of sarcopenia in Chinese community-dwelling elderly residents. Exp. Gerontol. 2020, 130, 110798. [CrossRef]

16. Zhao, W.; Zhang, Y.; Hou, L.; Xia, X.; Ge, M.; Liu, X.; Yue, J.; Dong, B. The association between systemic inflammatory markers and sarcopenia: Results from the West China Health and Aging Trend Study (WCHAT). Arch. Gerontol. Geriatr. 2021, $92,104262$. [CrossRef] [PubMed]

17. Metter, E.J.; Conwit, R.; Tobin, J.; Fozard, J.L. Age-Associated Loss of Power and Strength in the Upper Extremities in Women and Men. J. Gerontol. Ser. A Biol. Sci. Med. Sci. 1997, 52A, B267-B276. [CrossRef]

18. Yu, S.; Umapathysivam, K.; Visvanathan, R. Sarcopenia in older people. JBI Evid. Implement. 2014, 12, 227-243. [CrossRef]

19. Grimby, G.; Saltin, B. The ageing muscle. Clin. Physiol. 1983, 3, 209-218. [CrossRef]

20. Cruz-Jentoft, A.J.; Landi, F.; Schneider, S.M.; Zuniga, C.; Arai, H.; Boirie, Y.; Chen, L.-K.; Fielding, R.A.; Martin, F.C.; Michel, J.-P.; et al. Prevalence of and interventions for sarcopenia in ageing adults: A systematic review. Report of the International Sarcopenia Initiative (EWGSOP and IWGS). Age Ageing 2014, 43, 748-759. [CrossRef] [PubMed]

21. Dam, T.-T.; Peters, K.W.; Fragala, M.; Cawthon, P.M.; Harris, T.B.; McLean, R.; Shardell, M.; Alley, D.E.; Kenny, A.; Ferrucci, L.; et al. An Evidence-Based Comparison of Operational Criteria for the Presence of Sarcopenia. J. Gerontol. Ser. A Biol. Sci. Med. Sci. 2014, 69, 584-590. [CrossRef] [PubMed]

22. Liu, X.; Hou, L.; Xia, X.; Liu, Y.; Zuo, Z.; Zhang, Y.; Zhao, W.; Hao, Q.; Yue, J.; Dong, B. Prevalence of sarcopenia in multi ethnics adults and the association with cognitive impairment: Findings from West-China health and aging trend study. BMC Geriatr. 2020, 20, 63. [CrossRef]

23. Morley, J.E.; Anker, S.D.; von Haehling, S. Prevalence, incidence, and clinical impact of sarcopenia: Facts, numbers, and epidemiology-update 2014. J. Cachexia. Sarcopenia Muscle 2014, 5, 253-259. [CrossRef] 
24. Kim, T.N.; Choi, K.M. Sarcopenia: Definition, Epidemiology, and Pathophysiology. J. Bone Metab. 2013, 20, 1. [CrossRef] [PubMed]

25. Beaudart, C.; Rizzoli, R.; Bruyère, O.; Reginster, J.-Y.; Biver, E. Sarcopenia: Burden and challenges for public health. Arch. Public Health 2014, 72, 45. [CrossRef]

26. Lau, E.M.C.; Lynn, H.S.H.; Woo, J.W.; Kwok, T.C.Y.; Melton, L.J. Prevalence of and Risk Factors for Sarcopenia in Elderly Chinese Men and Women. J. Gerontol. Ser. A Biol. Sci. Med. Sci. 2005, 60, 213-216. [CrossRef] [PubMed]

27. Kim, T.N.; Park, M.S.; Yang, S.J.; Yoo, H.J.; Kang, H.J.; Song, W.; Seo, J.A.; Kim, S.G.; Kim, N.H.; Baik, S.H.; et al. Prevalence and Determinant Factors of Sarcopenia in Patients With Type 2 Diabetes: The Korean Sarcopenic Obesity Study (KSOS). Diabetes Care 2010, 33, 1497-1499. [CrossRef]

28. Limpawattana, P.; Kotruchin, P.; Pongchaiyakul, C. Sarcopenia in Asia. Osteoporos. Sarcopenia 2015, 1, 92-97. [CrossRef]

29. Shafiee, G.; Keshtkar, A.; Soltani, A.; Ahadi, Z.; Larijani, B.; Heshmat, R. Prevalence of sarcopenia in the world: A systematic review and meta-analysis of general population studies. J. Diabetes Metab. Disord. 2017, 16, 21. [CrossRef]

30. Yoshida, D.; Suzuki, T.; Shimada, H.; Park, H.; Makizako, H.; Doi, T.; Anan, Y.; Tsutsumimoto, K.; Uemura, K.; Ito, T.; et al. Using two different algorithms to determine the prevalence of sarcopenia. Geriatr. Gerontol. Int. 2014, 14, 46-51. [CrossRef] [PubMed]

31. Du, K.; Goates, S.; Arensberg, M.B.; Pereira, S.; Gaillard, T. Prevalence of Sarcopenia and Sarcopenic Obesity Vary with Race/Ethnicity and Advancing Age. Divers. Equal. Health Care 2018, 15, 175-183. [CrossRef]

32. Liu, X.; Hao, Q.; Hou, L.; Xia, X.; Zhao, W.; Zhang, Y.; Ge, M.; Liu, Y.; Zuo, Z.; Yue, J.; et al. Ethnic Groups Differences in the Prevalence of Sarcopenia Using the AWGS Criteria. J. Nutr. Health Aging 2020, 24, 665-671. [CrossRef]

33. Ardeljan, A.D.; Hurezeanu, R. Sarcopenia. In StatPearls; StatPearls Publishing: Treasure Island, FL, USA, 2021. Available online: https:/ / www.ncbi.nlm.nih.gov/books/NBK560813/ (accessed on 12 September 2021).

34. Yu, S.C.Y.; Khow, K.S.F.; Jadczak, A.D.; Visvanathan, R. Clinical Screening Tools for Sarcopenia and Its Management. Curr. Gerontol. Geriatr. Res. 2016, 2016, 5978523. [CrossRef]

35. Bai, A.; Xu, W.; Sun, J.; Liu, J.; Deng, X.; Wu, L.; Zou, X.; Zuo, J.; Zou, L.; Liu, Y.; et al. Associations of sarcopenia and its defining components with cognitive function in community-dwelling oldest old. BMC Geriatr. 2021, 21, 292. [CrossRef]

36. Yuenyongchaiwat, K.; Boonsinsukh, R. Sarcopenia and Its Relationships with Depression, Cognition, and Physical Activity in Thai Community-Dwelling Older Adults. Curr. Gerontol. Geriatr. Res. 2020, 2020, 8041489. [CrossRef]

37. Fábrega-Cuadros, R.; Hita-Contreras, F.; Martínez-Amat, A.; Jiménez-García, J.D.; Achalandabaso-Ochoa, A.; Lavilla-Lerma, L.; García-Garro, P.A.; Álvarez-Salvago, F.; Aibar-Almazán, A. Associations between the Severity of Sarcopenia and Health-Related Quality of Life in Community-Dwelling Middle-Aged and Older Adults. Int. J. Environ. Res. Public Health 2021, $18,8026$. [CrossRef]

38. Beaudart, C.; Biver, E.; Reginster, J.-Y.; Rizzoli, R.; Rolland, Y.; Bautmans, I.; Petermans, J.; Gillain, S.; Buckinx, F.; Dardenne, N.; et al. Validation of the SarQoL ${ }^{\circledR}$, a specific health-related quality of life questionnaire for Sarcopenia. J. Cachexia. Sarcopenia Muscle 2017, 8, 238-244. [CrossRef]

39. Beaudart, C.; Locquet, M.; Reginster, J.-Y.; Delandsheere, L.; Petermans, J.; Bruyère, O. Quality of life in sarcopenia measured with the SarQoL ${ }^{\circledR}$ : Impact of the use of different diagnosis definitions. Aging Clin. Exp. Res. 2018, 30, 307-313. [CrossRef]

40. Sun, D.S.; Lee, H.; Yim, H.W.; Won, H.S.; Ko, Y.H. The impact of sarcopenia on health-related quality of life in elderly people: Korean National Health and Nutrition Examination Survey. Korean J. Intern. Med. 2019, 34, 877-884. [CrossRef] [PubMed]

41. Xia, L.; Zhao, R.; Wan, Q.; Wu, Y.; Zhou, Y.; Wang, Y.; Cui, Y.; Shen, X.; Wu, X. Sarcopenia and adverse health-related outcomes: An umbrella review of meta-analyses of observational studies. Cancer Med. 2020, 9, 7964-7978. [CrossRef] [PubMed]

42. Souza, A.B.F.; Nascimento, D.A.C.; Rodrigues, I.J.M.; Charone, C.C.O.; Lopes, G.L.; Lima, R.S.; Sá, A.A.; Carneiro, T.X.; Moraes, N.S. Association between sarcopenia and diabetes in community dwelling elderly in the Amazon region-Viver Mais Project. Arch. Gerontol. Geriatr. 2019, 83, 121-125. [CrossRef] [PubMed]

43. Hayashi, M.; Abe, K.; Fujita, M.; Okai, K.; Takahashi, A.; Ohira, H. Association between sarcopenia and osteoporosis in chronic liver disease. Hepatol. Res. 2018, 48, 893-904. [CrossRef]

44. Choi, Y.I.; Chung, J.-W.; Park, D.K.; Ko, K.P.; Kim, K.O.; Kwon, K.A.; Kim, J.H.; Kim, Y.J. Sarcopenia is Independently Associated with an Increased Risk of Peptic Ulcer Disease: A Nationwide Population-Based Study. Medicina 2020, 56, 121. [CrossRef] [PubMed]

45. Peball, M.; Mahlknecht, P.; Werkmann, M.; Marini, K.; Murr, F.; Herzmann, H.; Stockner, H.; de Marzi, R.; Heim, B.; Djamshidian, A.; et al. Prevalence and Associated Factors of Sarcopenia and Frailty in Parkinson's Disease: A Cross-Sectional Study. Gerontology 2019, 65, 216-228. [CrossRef]

46. Waite, S.J.; Maitland, S.; Thomas, A.; Yarnall, A.J. Sarcopenia and frailty in individuals with dementia: A systematic review. Arch. Gerontol. Geriatr. 2021, 92, 104268. [CrossRef] [PubMed]

47. Kim, S.-H.; Sin, D.S.; Lim, J.-Y. Newly Diagnosed Sarcopenia and Alzheimer's Disease in an Older Patient With Chronic Inflammation. Ann. Geriatr. Med. Res. 2019, 23, 38-41. [CrossRef]

48. Liu, X.-G.; Tan, L.-J.; Lei, S.-F.; Liu, Y.-J.; Shen, H.; Wang, L.; Yan, H.; Guo, Y.-F.; Xiong, D.-H.; Chen, X.-D.; et al. Genome-wide Association and Replication Studies Identified TRHR as an Important Gene for Lean Body Mass. Am. J. Hum. Genet. 2009, 84, 418-423. [CrossRef]

49. Tan, L.-J.; Liu, S.-L.; Lei, S.-F.; Papasian, C.J.; Deng, H.-W. Molecular genetic studies of gene identification for sarcopenia. Hum. Genet. 2012, 131, 1-31. [CrossRef] 
50. Lin, C.-H.; Lin, C.-C.; Tsai, C.-W.; Chang, W.-S.; Yang, M.-D.; Bau, D.-T. A novel caveolin-1 biomarker for clinical outcome of sarcopenia. In Vivo 2014, 28, 383-389.

51. Ran, S.; Jiang, Z.-X.; He, X.; Liu, Y.; Zhang, Y.-X.; Zhang, L.; Pei, Y.-F.; Zhang, M.; Hai, R.; Gu, G.-S.; et al. Replication of FTO Gene associated with lean mass in a Meta-Analysis of Genome-Wide Association Studies. Sci. Rep. 2020, 10, 5057. [CrossRef] [PubMed]

52. Singh, A.N.; Gasman, B. Disentangling the genetics of sarcopenia: Prioritization of NUDT3 and KLF5 as genes for lean mass \& HLA-DQB1-AS1 for hand grip strength with the associated enhancing SNPs \& a scoring system. BMC Med. Genet. 2020, 21, 40. [CrossRef]

53. Urzi, F.; Pokorny, B.; Buzan, E. Pilot Study on Genetic Associations with Age-Related Sarcopenia. Front. Genet. 2021, 11, 1754. [CrossRef]

54. Daya, A.; Donaka, R.; Karasik, D. Zebrafish models of sarcopenia. Dis. Model. Mech. 2020, 13, dmm042689. [CrossRef] [PubMed]

55. Urano, T.; Inoue, S. Recent genetic discoveries in osteoporosis, sarcopenia and obesity. Endocr. J. 2015, 62, 475-484. [CrossRef] [PubMed]

56. Jones, G.; Trajanoska, K.; Santanasto, A.J.; Stringa, N.; Kuo, C.-L.; Atkins, J.L.; Lewis, J.R.; Duong, T.; Hong, S.; Biggs, M.L.; et al. Genome-wide meta-analysis of muscle weakness identifies 15 susceptibility loci in older men and women. Nat. Commun. 2021, 12, 654. [CrossRef]

57. Chen, Y.-Y.; Chiu, Y.-L.; Kao, T.-W.; Peng, T.-C.; Yang, H.-F.; Chen, W.-L. Cross-sectional associations among P3NP, HtrA, Hsp70, Apelin and sarcopenia in Taiwanese population. BMC Geriatr. 2021, 21, 192. [CrossRef] [PubMed]

58. Kashyap, L.; Perera, S.; Fisher, A.L. Identification of Novel Genes Involved in Sarcopenia Through RNAi Screening in Caenorhabditis elegans. J. Gerontol. Ser. A Biol. Sci. Med. Sci. 2012, 67A, 56-65. [CrossRef] [PubMed]

59. Van Tongeren, S.P.; Slaets, J.P.J.; Harmsen, H.J.M.; Welling, G.W. Fecal Microbiota Composition and Frailty. Appl. Environ. Microbiol. 2005, 71, 6438-6442. [CrossRef] [PubMed]

60. Peng, L.; Li, Z.-R.; Green, R.S.; Holzman, I.R.; Lin, J. Butyrate Enhances the Intestinal Barrier by Facilitating Tight Junction Assembly via Activation of AMP-Activated Protein Kinase in Caco-2 Cell Monolayers. J. Nutr. 2009, 139, 1619-1625. [CrossRef]

61. Londhe, P.; Guttridge, D.C. Inflammation induced loss of skeletal muscle. Bone 2015, 80, 131-142. [CrossRef] [PubMed]

62. Claesson, M.J.; Jeffery, I.B.; Conde, S.; Power, S.E.; O'Connor, E.M.; Cusack, S.; Harris, H.M.B.; Coakley, M.; Lakshminarayanan, B.; O'Sullivan, O.; et al. Gut microbiota composition correlates with diet and health in the elderly. Nature 2012, 488, 178-184. [CrossRef]

63. Picca, A.; Ponziani, F.R.; Calvani, R.; Marini, F.; Biancolillo, A.; Coelho-Júnior, H.J.; Gervasoni, J.; Primiano, A.; Putignani, L.; Del Chierico, F.; et al. Gut Microbial, Inflammatory and Metabolic Signatures in Older People with Physical Frailty and Sarcopenia: Results from the BIOSPHERE Study. Nutrients 2019, 12, 65. [CrossRef]

64. Picca, A.; Calvani, R.; Cesari, M.; Landi, F.; Bernabei, R.; Coelho-Júnior, H.J.; Marzetti, E. Biomarkers of Physical Frailty and Sarcopenia: Coming up to the Place? Int. J. Mol. Sci. 2020, 21, 5635. [CrossRef]

65. Kang, L.; Li, P.; Wang, D.; Wang, T.; Hao, D.; Qu, X. Alterations in intestinal microbiota diversity, composition, and function in patients with sarcopenia. Sci. Rep. 2021, 11, 4628. [CrossRef]

66. Tieland, M.; Trouwborst, I.; Clark, B.C. Skeletal muscle performance and ageing. J. Cachexia. Sarcopenia Muscle 2018, 9, 3-19. [CrossRef]

67. Tani, Y.; Sasaki, Y.; Haseda, M.; Kondo, K.; Kondo, N. Eating alone and depression in older men and women by cohabitation status: The JAGES longitudinal survey. Age Ageing 2015, 44, 1019-1026. [CrossRef] [PubMed]

68. Boulos, C.; Salameh, P.; Barberger-Gateau, P. Social isolation and risk for malnutrition among older people. Geriatr. Gerontol. Int. 2017, 17, 286-294. [CrossRef] [PubMed]

69. Guigoz, Y. The Mini Nutritional Assessment $\left(\mathrm{MNA}^{\circledR}\right)$ Review of the Literature-What Does It Tell Us? J. Nutr. Health Aging 2005, 10, 466-485, discussion 485.

70. Vellas, B.; Villars, H.; Abellan, G.; Soto, M.E.; Rolland, Y.; Guigoz, Y.; Morley, J.E.; Chumlea, W.; Salva, A.; Rubenstein, L.Z.; et al. Overview of the MNA-Its history and challenges. J. Nutr. Health Aging 2006, 10, 456-463; discussion $463-465$.

71. Kim, B.; Lee, G.; Seo, Y.; Seo, A.; Kim, M.; Seo, S.; Park, K.S. Nutrition and Psychosocial Factors were Associated with Possible Sarcopenia According to AWGS 2019. Res. Square Prepr. 2020. [CrossRef]

72. McAuley, E.; Konopack, J.F.; Morris, K.S.; Motl, R.W.; Hu, L.; Doerksen, S.E.; Rosengren, K. Physical Activity and Functional Limitations in Older Women: Influence of Self-Efficacy. J. Gerontol. Ser. B Psychol. Sci. Soc. Sci. 2006, 61, P270-P277. [CrossRef] [PubMed]

73. Rosengren, K.S.; McAuley, E.; Mihalko, S.L. Gait adjustments in older adults: Activity and efficacy influences. Psychol. Aging 1998, 13, 375-386. [CrossRef]

74. Cheung, C.; Wyman, J.F.; Savik, K. Adherence to a Yoga Program in Older Women with Knee Osteoarthritis. J. Aging Phys. Act. 2016, 24, 181-188. [CrossRef]

75. McAuley, E.; Morris, K.S.; Doerksen, S.E.; Motl, R.W.; Liang, H.; White, S.M.; Wójcicki, T.R.; Rosengren, K. Effects of Change in Physical Activity on Physical Function Limitations in Older Women: Mediating Roles of Physical Function Performance and Self-Efficacy. J. Am. Geriatr. Soc. 2007, 55, 1967-1973. [CrossRef]

76. Cumming, R.G.; Salkeld, G.; Thomas, M.; Szonyi, G. Prospective Study of the Impact of Fear of Falling on Activities of Daily Living, SF-36 Scores, and Nursing Home Admission. J. Gerontol. Ser. A Biol. Sci. Med. Sci. 2000, 55, M299-M305. [CrossRef] 
77. Brouwer, B.; Musselman, K.; Culham, E. Physical Function and Health Status among Seniors with and without a Fear of Falling. Gerontology 2004, 50, 135-141. [CrossRef]

78. Jefferis, B.J.; Iliffe, S.; Kendrick, D.; Kerse, N.; Trost, S.; Lennon, L.T.; Ash, S.; Sartini, C.; Morris, R.W.; Wannamethee, S.G.; et al. How are falls and fear of falling associated with objectively measured physical activity in a cohort of community-dwelling older men? BMC Geriatr. 2014, 14, 114. [CrossRef]

79. Stenholm, S.; Koster, A.; Valkeinen, H.; Patel, K.V.; Bandinelli, S.; Guralnik, J.M.; Ferrucci, L. Association of Physical Activity History With Physical Function and Mortality in Old Age. J. Gerontol. Ser. A Biol. Sci. Med. Sci. 2016, 71, 496-501. [CrossRef] [PubMed]

80. Taani, M. Cognitive and Psychosocial Factors Associated with Sarcopenia in Older Adults. Ph.D. Thesis, The University of Wisconsin-Milwaukee, Milwaukee, WI, USA, 2017.

81. Taani, M.H.; Siglinsky, E.; Kovach, C.R.; Buehring, B. Psychosocial Factors Associated With Reduced Muscle Mass, Strength, and Function in Residential Care Apartment Complex Residents. Res. Gerontol. Nurs. 2018, 11, 238-248. [CrossRef] [PubMed]

82. Rom, O.; Kaisari, S.; Aizenbud, D.; Reznick, A.Z. Lifestyle and Sarcopenia-Etiology, Prevention and Treatment. Rambam Maimonides Med. J. 2012, 3, e0024. [CrossRef] [PubMed]

83. Tzeng, P.-L.; Lin, C.-Y.; Lai, T.-F.; Huang, W.-C.; Pien, E.; Hsueh, M.-C.; Lin, K.-P.; Park, J.-H.; Liao, Y. Daily lifestyle behaviors and risks of sarcopenia among older adults. Arch. Public Health 2020, 78, 113. [CrossRef]

84. Özoğul, F.; Kuley, E.; Özoğul, Y.; Özoğul, İ. The Function of Lactic Acid Bacteria on Biogenic Amines Production by Food-Borne Pathogens in Arginine Decarboxylase Broth. Food Sci. Technol. Res. 2012, 18, 795-804. [CrossRef]

85. Calvani, R.; Martone, A.M.; Marzetti, E.; Onder, G.; Savera, G.; Lorenzi, M.; Serafini, E.; Bernabei, R.; Landi, F. Pre-Hospital Dietary Intake Correlates with Muscle Mass at the Time of Fracture in Older Hip-Fractured Patients. Front. Aging Neurosci. 2014, 6, 269. [CrossRef] [PubMed]

86. Cruz-Jentoft, A.J.; Landi, F.; Topinková, E.; Michel, J.-P. Understanding sarcopenia as a geriatric syndrome. Curr. Opin. Clin. Nutr. Metab. Care 2010, 13, 1-7. [CrossRef] [PubMed]

87. Marzetti, E.; Calvani, R.; Tosato, M.; Cesari, M.; Di Bari, M.; Cherubini, A.; Collamati, A.; D’Angelo, E.; Pahor, M.; Bernabei, R.; et al. Sarcopenia: An overview. Aging Clin. Exp. Res. 2017, 29, 11-17. [CrossRef] [PubMed]

88. Curcio, F.; Ferro, G.; Basile, C.; Liguori, I.; Parrella, P.; Pirozzi, F.; Della-Morte, D.; Gargiulo, G.; Testa, G.; Tocchetti, C.G.; et al. Biomarkers in sarcopenia: A multifactorial approach. Exp. Gerontol. 2016, 85, 1-8. [CrossRef]

89. Sataranatarajan, K.; Qaisar, R.; Davis, C.; Sakellariou, G.K.; Vasilaki, A.; Zhang, Y.; Liu, Y.; Bhaskaran, S.; McArdle, A.; Jackson, M.; et al. Neuron specific reduction in CuZnSOD is not sufficient to initiate a full sarcopenia phenotype. Redox Biol. 2015, 5, 140-148. [CrossRef]

90. Marzetti, E.; Calvani, R.; Lorenzi, M.; Marini, F.; D’Angelo, E.; Martone, A.M.; Celi, M.; Tosato, M.; Bernabei, R.; Landi, F. Serum levels of $\mathrm{C}$-terminal agrin fragment (CAF) are associated with sarcopenia in older hip fractured patients. Exp. Gerontol. 2014, 60, 79-82. [CrossRef]

91. Hettwer, S.; Dahinden, P.; Kucsera, S.; Farina, C.; Ahmed, S.; Fariello, R.; Drey, M.; Sieber, C.C.; Vrijbloed, J.W. Elevated levels of a C-terminal agrin fragment identifies a new subset of sarcopenia patients. Exp. Gerontol. 2013, 48, 69-75. [CrossRef]

92. Qaisar, R.; Karim, A.; Muhammad, T.; Shah, I. Circulating Biomarkers of Accelerated Sarcopenia in Respiratory Diseases. Biology 2020, 9, 322. [CrossRef]

93. Qaisar, R.; Karim, A.; Muhammad, T.; Shah, I.; Khan, J. Prediction of sarcopenia using a battery of circulating biomarkers. Sci. Rep. 2021, 11, 8632. [CrossRef]

94. Sakuma, K.; Yamaguchi, A. Sarcopenia and Age-Related Endocrine Function. Int. J. Endocrinol. 2012, 2012, 127362. [CrossRef]

95. Bhasin, S.; Calof, O.M.; Storer, T.W.; Lee, M.L.; Mazer, N.A.; Jasuja, R.; Montori, V.M.; Gao, W.; Dalton, J.T. Drug insight: Testosterone and selective androgen receptor modulators as anabolic therapies for chronic illness and aging. Nat. Clin. Pract. Endocrinol. Metab. 2006, 2, 146-159. [CrossRef] [PubMed]

96. Araujo, A.B.; Travison, T.G.; Bhasin, S.; Esche, G.R.; Williams, R.E.; Clark, R.V.; McKinlay, J.B. Association Between Testosterone and Estradiol and Age-Related Decline in Physical Function in a Diverse Sample of Men. J. Am. Geriatr. Soc. 2008, 56, $2000-2008$. [CrossRef]

97. Hyde, Z.; Flicker, L.; Almeida, O.P.; Hankey, G.J.; McCaul, K.A.; Chubb, S.A.P.; Yeap, B.B. Low Free Testosterone Predicts Frailty in Older Men: The Health in Men Study. J. Clin. Endocrinol. Metab. 2010, 95, 3165-3172. [CrossRef] [PubMed]

98. Krasnoff, J.B.; Basaria, S.; Pencina, M.J.; Jasuja, G.K.; Vasan, R.S.; Ulloor, J.; Zhang, A.; Coviello, A.; Kelly-Hayes, M.; D’Agostino, R.B.; et al. Free Testosterone Levels Are Associated with Mobility Limitation and Physical Performance in Community-Dwelling Men: The Framingham Offspring Study. J. Clin. Endocrinol. Metab. 2010, 95, 2790-2799. [CrossRef]

99. Priego, T.; Martín, A.I.; González-Hedström, D.; Granado, M.; López-Calderón, A. Role of hormones in sarcopenia. In Vitamins and Hormones; Academic Press: Cambridge, MA, USA, 2021; pp. 535-570.

100. Petermann-Rocha, F.; Gray, S.R.; Pell, J.P.; Celis-Morales, C.; Ho, F.K. Biomarkers Profile of People With Sarcopenia: A Crosssectional Analysis from UK Biobank. J. Am. Med. Dir. Assoc. 2020, 21, 2017.e1-2017.e9. [CrossRef] [PubMed]

101. Valenti, G.; Denti, L.; Maggio, M.; Ceda, G.; Volpato, S.; Bandinelli, S.; Ceresini, G.; Cappola, A.; Guralnik, J.M.; Ferrucci, L. Effect of DHEAS on Skeletal Muscle Over the Life Span: The InCHIANTI Study. J. Gerontol. Ser. A Biol. Sci. Med. Sci. 2004, 59, M466-M472. [CrossRef] 
102. Kostka, T.; Arsac, L.M.; Patricot, M.C.; Berthouze, S.E.; Lacour, J.-R.; Bonnefoy, M. Leg extensor power and dehydroepiandrosterone sulfate, insulin-like growth factor-I and testosterone in healthy active elderly people. Eur. J. Appl. Physiol. 2000, 82, 83-90. [CrossRef] [PubMed]

103. Bischoff-Ferrari, H.A.; Orav, E.J. Additive benefit of higher testosterone levels and vitamin D plus calcium supple_mentation in regard to fall risk reduction among older men and women. Osteoporos. Int. 2008, 19, 1307-1314. [CrossRef]

104. Villareal, D.; Holloszy, J. Effect of DHEA on Abdominal Fat and Insulin Action in Elderly Women and Men. JAMA 2004, 292, 2243-2248. [CrossRef] [PubMed]

105. Morley, J.E. Hormones and Sarcopenia. Curr. Pharm. Des. 2017, 23, 4484-4492. [CrossRef]

106. Bian, A.; Ma, Y.; Zhou, X.; Guo, Y.; Wang, W.; Zhang, Y.; Wang, X. Association between sarcopenia and levels of growth hormone and insulin-like growth factor-1 in the elderly. BMC Musculoskelet. Disord. 2020, 21, 214. [CrossRef]

107. Kwak, J.Y.; Hwang, H.; Kim, S.-K.; Choi, J.Y.; Lee, S.-M.; Bang, H.; Kwon, E.-S.; Lee, K.-P.; Chung, S.G.; Kwon, K.-S. Prediction of sarcopenia using a combination of multiple serum biomarkers. Sci. Rep. 2018, 8, 8574. [CrossRef] [PubMed]

108. Sakuma, K.; Aoi, W.; Yamaguchi, A. The Intriguing Regulators of Muscle Mass in Sarcopenia and Muscular Dystrophy. Front. Aging Neurosci. 2014, 6, 230. [CrossRef]

109. Baczek, J.; Silkiewicz, M.; Wojszel, Z.B. Myostatin as a Biomarker of Muscle Wasting and other Pathologies-State of the Art and Knowledge Gaps. Nutrients 2020, 12, 2401. [CrossRef]

110. Laurent, M.R.; Dupont, J.; Dejaeger, M.; Gielen, E. Myostatin: A Powerful Biomarker for Sarcopenia and Frailty? Gerontology 2019, 65, 383-384. [CrossRef] [PubMed]

111. Chen, J.L.; Walton, K.L.; Winbanks, C.E.; Murphy, K.T.; Thomson, R.E.; Makanji, Y.; Qian, H.; Lynch, G.S.; Harrison, C.A.; Gregorevic, P. Elevated expression of activins promotes muscle wasting and cachexia. FASEB J. 2014, 28, 1711-1723. [CrossRef]

112. Gilson, H.; Schakman, O.; Kalista, S.; Lause, P.; Tsuchida, K.; Thissen, J.-P. Follistatin induces muscle hypertrophy through satellite cell proliferation and inhibition of both myostatin and activin. Am. J. Physiol. Metab. 2009, 297, E157-E164. [CrossRef] [PubMed]

113. Choi, K.; Jang, H.Y.; Ahn, J.M.; Hwang, S.H.; Chung, J.W.; Choi, Y.S.; Kim, J.-W.; Jang, E.S.; Choi, G.H.; Jeong, S.-H. The association of the serum levels of myostatin, follistatin, and interleukin- 6 with sarcopenia, and their impacts on survival in patients with hepatocellular carcinoma. Clin. Mol. Hepatol. 2020, 26, 492-505. [CrossRef]

114. Bloch, S.A.A.; Lee, J.Y.; Syburra, T.; Rosendahl, U.; Griffiths, M.J.D.; Kemp, P.R.; Polkey, M.I. Increased expression of GDF-15 may mediate ICU-acquired weakness by down-regulating muscle microRNAs. Thorax 2015, 70, 219-228. [CrossRef]

115. Kim, M.; Walston, J.D.; Won, C.W. Associations between Elevated Growth Differentiation Factor-15 and Sarcopenia among Community-dwelling Older Adults. J. Gerontol. Ser. A 2021, glab201. [CrossRef] [PubMed]

116. Sartori, R.; Gregorevic, P.; Sandri, M. TGF $\beta$ and BMP signaling in skeletal muscle: Potential significance for muscle-related disease. Trends Endocrinol. Metab. 2014, 25, 464-471. [CrossRef] [PubMed]

117. Zhao, M.; Zhou, X.; Yuan, C.; Li, R.; Ma, Y.; Tang, X. Association between serum irisin concentrations and sarcopenia in patients with liver cirrhosis: A cross-sectional study. Sci. Rep. 2020, 10, 16093. [CrossRef] [PubMed]

118. Chang, J.S.; Kim, T.H.; Nguyen, T.T.; Park, K.-S.; Kim, N.; Kong, I.D. Circulating irisin levels as a predictive biomarker for sarcopenia: A cross-sectional community-based study. Geriatr. Gerontol. Int. 2017, 17, 2266-2273. [CrossRef] [PubMed]

119. Medeiros, M.C.; Rocha, N.; Bandeira, E.; Dantas, I.; Chaves, C.; Oliveira, M.; Bandeira, F. Serum Sclerostin, Body Composition, and Sarcopenia in Hemodialysis Patients with Diabetes. Int. J. Nephrol. 2020, 2020, 4596920. [CrossRef]

120. Delezie, J.; Weihrauch, M.; Maier, G.; Tejero, R.; Ham, D.J.; Gill, J.F.; Karrer-Cardel, B.; Rüegg, M.A.; Tabares, L.; Handschin, C. BDNF is a mediator of glycolytic fiber-type specification in mouse skeletal muscle. Proc. Natl. Acad. Sci. USA 2019, 116, 16111-16120. [CrossRef] [PubMed]

121. Henrotin, Y.; Cordier, B.; Labasse, A.; Poelen Vander, S.; Boileau, C.; Costes, B.; L'hôte, C. Identification and characterization of new biochemical markers for sarcopenia. Osteoarthr. Cartil. 2019, 27, S101. [CrossRef]

122. Kochlik, B.; Stuetz, W.; Pérès, K.; Féart, C.; Tegner, J.; Rodriguez-Mañas, L.; Grune, T.; Weber, D. Associations of Plasma 3-Methylhistidine with Frailty Status in French Cohorts of the FRAILOMIC Initiative. J. Clin. Med. 2019, 8, 1010. [CrossRef]

123. L'hôte, C.; Cordier, B.; Labasse, A.; Boileau, C.; Costes, B.; Henrotin, Y. Identification of new biomarkers for sarcopenia and characterization of cathepsin D biomarker. JCSM Rapid Commun. 2021, 4, 122-132. [CrossRef]

124. Watanabe, S.; Sato, K.; Hasegawa, N.; Kurihara, T.; Matsutani, K.; Sanada, K.; Hamaoka, T.; Fujita, S.; Iemitsu, M. Serum C1q as a novel biomarker of sarcopenia in older adults. FASEB J. 2015, 29, 1003-1010. [CrossRef]

125. Tseng, S.-H.; Lee, W.-J.; Peng, L.-N.; Lin, M.-H.; Chen, L.-K. Associations between hemoglobin levels and sarcopenia and its components: Results from the I-Lan longitudinal study. Exp. Gerontol. 2021, 150, 111379. [CrossRef]

126. Van Dronkelaar, C.; van Velzen, A.; Abdelrazek, M.; van der Steen, A.; Weijs, P.J.M.; Tieland, M. Minerals and Sarcopenia; the Role of Calcium, Iron, Magnesium, Phosphorus, Potassium, Selenium, Sodium, and Zinc on Muscle Mass, Muscle Strength, and Physical Performance in Older Adults: A Systematic Review. J. Am. Med. Dir. Assoc. 2018, 19, 6-11.e3. [CrossRef]

127. Mithal, A.; Wahl, D.A.; Bonjour, J.-P.; Burckhardt, P.; Dawson-Hughes, B.; Eisman, J.A.; El-Hajj Fuleihan, G.; Josse, R.G.; Lips, P.; Morales-Torres, J. Global vitamin D status and determinants of hypovitaminosis D. Osteoporos. Int. 2009, 20, 1807-1820. [CrossRef]

128. Remelli, F.; Vitali, A.; Zurlo, A.; Volpato, S. Vitamin D Deficiency and Sarcopenia in Older Persons. Nutrients 2019, $11,2861$. [CrossRef]

129. Ganapathy, A.; Nieves, J.W. Nutrition and Sarcopenia-What Do We Know? Nutrients 2020, 12, 1755. [CrossRef] 
130. Komici, K.; Dello Iacono, A.; De Luca, A.; Perrotta, F.; Bencivenga, L.; Rengo, G.; Rocca, A.; Guerra, G. Adiponectin and Sarcopenia: A Systematic Review With Meta-Analysis. Front. Endocrinol. 2021, 12, 329. [CrossRef]

131. Yang, Z.-Y.; Chen, W.-L. Examining the Association Between Serum Leptin and Sarcopenic Obesity. J. Inflamm. Res. 2021, 14, 3481-3487. [CrossRef]

132. Macchi, C.; Molino-Lova, R.; Polcaro, P.; Guarducci, L.; Lauretani, F.; Cecchi, F.; Bandinelli, S.; Guralnik, J.M.; Ferrucci, L. Higher circulating levels of uric acid are prospectively associated with better muscle function in older persons. Mech. Ageing Dev. 2008, 129, 522-527. [CrossRef]

133. Tuttle, C.S.L.; Thang, L.A.N.; Maier, A.B. Markers of inflammation and their association with muscle strength and mass: A systematic review and meta-analysis. Ageing Res. Rev. 2020, 64, 101185. [CrossRef]

134. Mochizuki, T.; Yano, K.; Ikari, K.; Okazaki, K. Sarcopenia-associated factors in Japanese patients with rheumatoid arthritis: A cross-sectional study. Geriatr. Gerontol. Int. 2019, 19, 907-912. [CrossRef]

135. Bano, G.; Trevisan, C.; Carraro, S.; Solmi, M.; Luchini, C.; Stubbs, B.; Manzato, E.; Sergi, G.; Veronese, N. Inflammation and sarcopenia: A systematic review and meta-analysis. Maturitas 2017, 96, 10-15. [CrossRef]

136. Sell, H.; Habich, C.; Eckel, J. Adaptive immunity in obesity and insulin resistance. Nat. Rev. Endocrinol. 2012, 8, 709-716. [CrossRef]

137. Nelke, C.; Dziewas, R.; Minnerup, J.; Meuth, S.G.; Ruck, T. Skeletal muscle as potential central link between sarcopenia and immune senescence. EBioMedicine 2019, 49, 381-388. [CrossRef]

138. Ogawa, K.; Kim, H.; Shimizu, T.; Abe, S.; Shiga, Y.; Calderwood, S.K. Plasma heat shock protein 72 as a biomarker of sarcopenia in elderly people. Cell Stress Chaperones 2012, 17, 349-359. [CrossRef]

139. Calvani, R.; Picca, A.; Marini, F.; Biancolillo, A.; Gervasoni, J.; Persichilli, S.; Primiano, A.; Coelho-Junior, H.J.; Cesari, M.; Bossola, M.; et al. Identification of biomarkers for physical frailty and sarcopenia through a new multi-marker approach: Results from the BIOSPHERE study. GeroScience 2021, 43, 727-740. [CrossRef]

140. Oflazoglu, U.; Alacacioglu, A.; Varol, U.; Kucukzeybek, Y.; Salman, T.; Onal, H.T.; Yilmaz, H.E.; Yildiz, Y.; Taskaynatan, H.; Saray, S.; et al. The role of inflammation in adjuvant chemotherapy-induced sarcopenia (Izmir Oncology Group (IZOG) study). Support. Care Cancer 2020, 28, 3965-3977. [CrossRef]

141. Ko, F.; Abadir, P.; Marx, R.; Westbrook, R.; Cooke, C.; Yang, H.; Walston, J. Impaired mitochondrial degradation by autophagy in the skeletal muscle of the aged female interleukin 10 null mouse. Exp. Gerontol. 2016, 73, 23-27. [CrossRef] [PubMed]

142. Marzetti, E.; Calvani, R.; Lorenzi, M.; Tanganelli, F.; Picca, A.; Bossola, M.; Menghi, A.; Bernabei, R.; Landi, F. Association between myocyte quality control signaling and sarcopenia in old hip-fractured patients: Results from the Sarcopenia in HIp FracTure (SHIFT) exploratory study. Exp. Gerontol. 2016, 80, 1-5. [CrossRef]

143. Cacciatore, F.; Della-Morte, D.; Basile, C.; Curcio, F.; Liguori, I.; Roselli, M.; Gargiulo, G.; Galizia, G.; Bonaduce, D.; Abete, P. Butyryl-cholinesterase is related to muscle mass and strength. A new biomarker to identify elderly subjects at risk of sarcopenia. Biomark. Med. 2015, 9, 669-678. [CrossRef]

144. Kawamoto, R.; Kohara, K.; Katoh, T.; Kusunoki, T.; Ohtsuka, N.; Abe, M.; Kumagi, T.; Miki, T. Changes in oxidized low-density lipoprotein cholesterol are associated with changes in handgrip strength in Japanese community-dwelling persons. Endocrine 2015, 48, 871-877. [CrossRef]

145. Semba, R.D.; Lauretani, F.; Ferrucci, L. Carotenoids as protection against sarcopenia in older adults. Arch. Biochem. Biophys. 2007, 458, 141-145. [CrossRef]

146. Semba, R.D.; Blaum, C.; Guralnik, J.M.; Moncrief, D.T.; Ricks, M.O.; Fried, L.P. Carotenoid and vitamin E status are associated with indicators of sarcopenia among older women living in the community. Aging Clin. Exp. Res. 2003, 15, 482-487. [CrossRef]

147. Hunter, G.R.; Singh, H.; Carter, S.J.; Bryan, D.R.; Fisher, G. Sarcopenia and Its Implications for Metabolic Health. J. Obes. 2019, 2019, 8031705. [CrossRef] [PubMed]

148. Tournadre, A.; Vial, G.; Capel, F.; Soubrier, M.; Boirie, Y. Sarcopenia. Jt. Bone Spine 2019, 86, 309-314. [CrossRef] [PubMed]

149. Chang, S.-F.; Lin, P.-L. Systematic Literature Review and Meta-Analysis of the Association of Sarcopenia with Mortality. Worldviews Evid.-Based Nurs. 2016, 13, 153-162. [CrossRef]

150. Beaudart, C.; Zaaria, M.; Pasleau, F.; Reginster, J.-Y.; Bruyère, O. Health Outcomes of Sarcopenia: A Systematic Review and Meta-Analysis. PLoS ONE 2017, 12, e0169548. [CrossRef]

151. Kirwan, R.; McCullough, D.; Butler, T.; de Heredia, F.P.; Davies, I.G.; Stewart, C. Sarcopenia during COVID-19 lockdown restrictions: Long-term health effects of short-term muscle loss. GeroScience 2020, 42, 1547-1578. [CrossRef] [PubMed]

152. De Mello, R.G.B.; Dalla Corte, R.R.; Gioscia, J.; Moriguchi, E.H. Effects of Physical Exercise Programs on Sarcopenia Management, Dynapenia, and Physical Performance in the Elderly: A Systematic Review of Randomized Clinical Trials. J. Aging Res. 2019, 2019, 1959486. [CrossRef]

153. Vitale, J.A.; Bonato, M.; Borghi, S.; Messina, C.; Albano, D.; Corbetta, S.; Sconfienza, L.M.; Banfi, G. Home-Based Resistance Training for Older Subjects during the COVID-19 Outbreak in Italy: Preliminary Results of a Six-Months RCT. Int. J. Environ. Res. Public Health 2020, 17, 9533. [CrossRef] [PubMed]

154. Marcell, T.J. Review Article: Sarcopenia: Causes, Consequences, and Preventions. J. Gerontol. Ser. A Biol. Sci. Med. Sci. 2003, 58, M911-M916. [CrossRef] 
155. Bonato, M.; Turrini, F.; De Zan, V.; Meloni, A.; Plebani, M.; Brambilla, E.; Giordani, A.; Vitobello, C.; Caccia, R.; Piacentini, M.F.; et al. A Mobile Application for Exercise Intervention in People Living with HIV. Med. Sci. Sport. Exerc. 2020, 52, 425-433. [CrossRef] [PubMed]

156. Sousa, A.S.; Guerra, R.S.; Fonseca, I.; Pichel, F.; Ferreira, S.; Amaral, T.F. Financial impact of sarcopenia on hospitalization costs. Eur. J. Clin. Nutr. 2016, 70, 1046-1051. [CrossRef] [PubMed] 